\title{
Bayesian inference of phylogeny, morphology and range evolution reveals a complex evolutionary history in St. John's wort (Hypericum)
}

\author{
Andrea Sánchez Meseguer ${ }^{\mathrm{a}, *}$, Juan Jose Aldasoro ${ }^{\mathrm{b}}$, Isabel Sanmartín ${ }^{\mathrm{a}, *}$ \\ ${ }^{a}$ Department of Biodiversity and Conservation, Real Jardín Bótanico-CSIC, Spain \\ ${ }^{\mathrm{b}}$ Department of Biodiversity, Institut Botanic de Barcelona-CSIC, Spain
}

\section{A R T I C L E I N F O}

\section{Article history:}

Received 6 November 2012

Revised 10 January 2013

Accepted 6 February 2013

Available online 19 February 2013

\section{Keywords:}

Hypericum

Phylogeny

Character evolution

Biogeography

DNA

Bayesian

\begin{abstract}
A B S T R A C T
The genus Hypericum L. ("St. John's wort", Hypericaceae) comprises nearly 500 species of shrubs, trees and herbs distributed mainly in temperate regions of the Northern Hemisphere, but also in high-altitude tropical and subtropical areas. Until now, molecular phylogenetic hypotheses on infra-generic relationships have been based solely on the nuclear marker ITS. Here, we used a full Bayesian approach to simultaneously reconstruct phylogenetic relationships, divergence times, and patterns of morphological and range evolution in Hypericum, using nuclear (ITS) and plastid DNA sequences ( $p s b$-trnH, trnS-trnG, trnL-trnF) of 186 species representing 33 of the 36 described morphological sections. Consistent with other studies, we found that corrections of the branch length prior helped recover more realistic branch lengths in by-gene partitioned Bayesian analyses, but the effect was also seen within single genes if the overall mutation rate differed considerably among sites or regions. Our study confirms that Hypericum is not monophyletic with the genus Triadenum embedded within, and rejects the traditional infrageneric classification, with many sections being para- or polyphyletic. The small Western Palearctic sections Elodes and Adenotrias are the sister-group of a geographic dichotomy between a mainly New World clade and a large Old World clade. Bayesian reconstruction of morphological character states and range evolution show a complex pattern of morphological plasticity and inter-continental movement within the genus. The ancestors of Hypericum were probably tropical shrubs that migrated from Africa to the Palearctic in the Early Tertiary, concurrent with the expansion of tropical climates in northern latitudes. Global climate cooling from the Mid Tertiary onwards might have promoted adaptation to temperate conditions in some lineages, such as the development of the herbaceous habit or unspecialized corollas. (c) 2013 Elsevier Inc. All rights reserved.
\end{abstract}

\section{Introduction}

Bayesian inference techniques have become very popular in phylogenetics because of the relative ease with which these techniques allow biologists to infer evolutionary patterns using complex and realistic models (Ronquist, 2004). Markov Chain Monte Carlo Bayesian approaches have now been developed to answer evolutionary questions, ranging from the time and place of origin of lineages to inferring the evolution of morphological traits, while accounting for phylogenetic and model uncertainty (Drummond and Rambaut, 2007; Huelsenbeck and Bollback, 2001; Lemey et al., 2009; Ronquist and Sanmartín, 2011; Sanmartin et al., 2008). Here, we use this full Bayesian approach (Ronquist, 2004) to simultaneously reconstruct phylogenetic relationships, lineage

* Corresponding authors. Address: Plaza de Murillo 2, 28014 Madrid, Spain. Fax: +34914200157.

E-mail addresses: asanchezmeseguer@gmail.com (A.S. Meseguer), isanmartin@ rjb.csic.es (I. Sanmartín). divergence times and ancestral areas in the old worldwide distributed plant genus Hypericum (Nürk and Blattner, 2010; Robson, 1981), while integrating out uncertainty concerning tree topology and other model parameters.

Hypericum L. represents one of the 100 largest angiosperm genera of the world (Carine and Christenhusz, 2010), with over 496 species (including other Hypericeae genera (Nürk et al., 2012), or 500 in the most recent Robson's (2012) revision) of trees, shrubs and herbs. The genus is distributed in almost every continent and ecosystem, being absent only in the poles, arid deserts, and low-altitude tropical areas (Fig. 1) (Robson, 1977). Hypericum is a relatively old genus as suggested by its fossil record dating back to the Early-Mid Tertiary, ca. 37-34 Ma (Meseguer and Sanmartín, 2012). Some Hypericum species, such as Hypericum perforatum L. (common St. John's wort), are economically important in pharmacology because of their active compounds hypericine and pseudo-hypericine, which are used as painkillers, antidepressants or anticancer treatments (Barnes et al., 2001). In this aspect, a phylogenetic hypothesis for the genus Hypericum could be interesting for bioprospecting. 


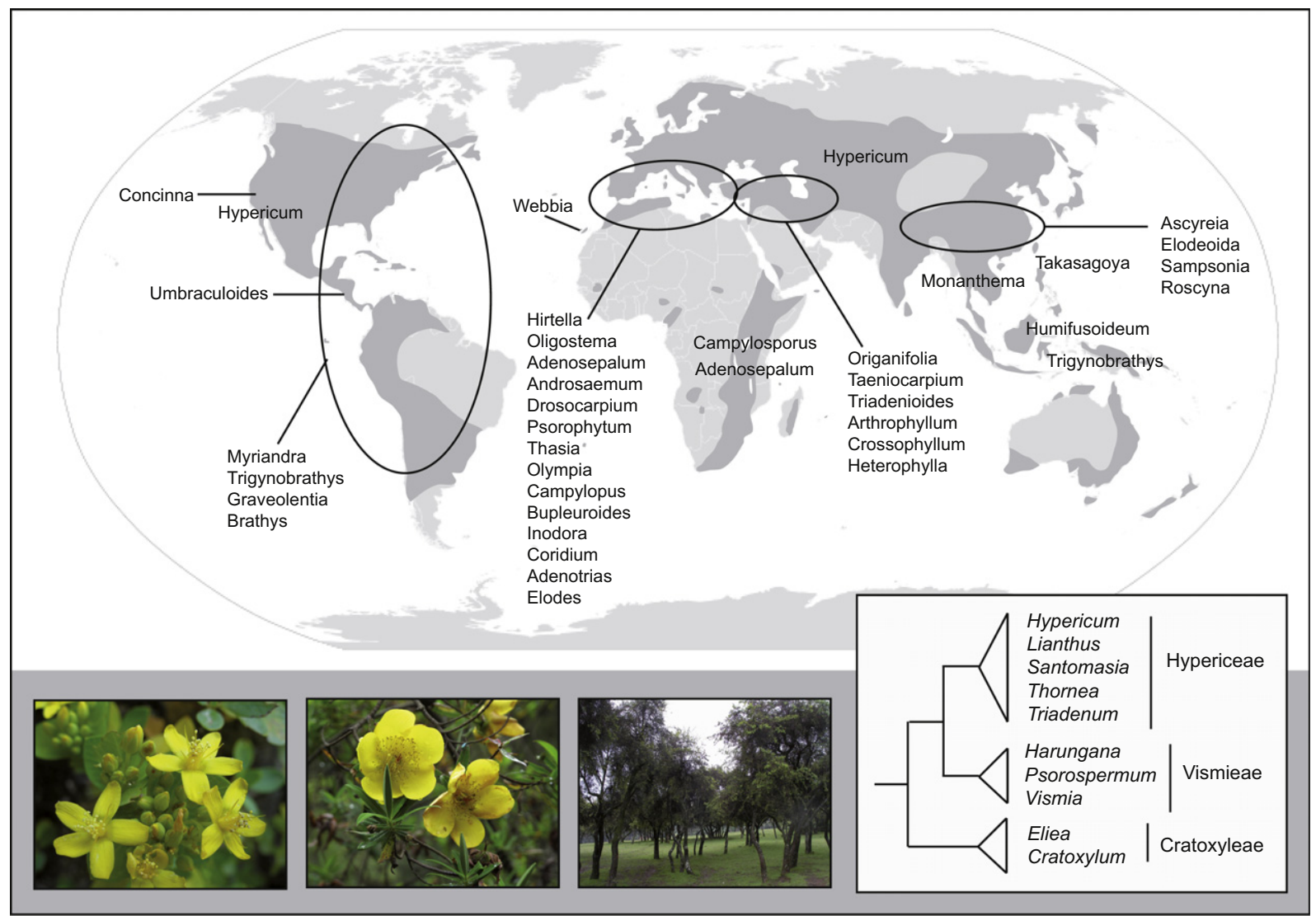

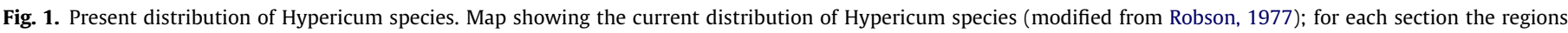

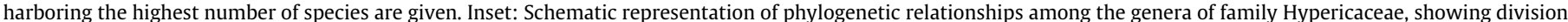

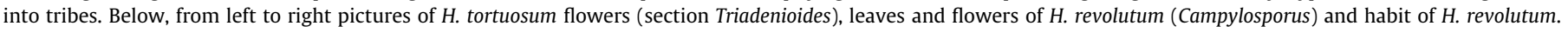

Current Angiosperm classification (APGIII 2009, Stevens, 2007) includes the genus Hypericum in the family Hypericaceae, belonging to the large clade of mostly tropical plants known as the "clusioid clade" (Davis et al., 2005; Gustafsson and Persson, 2002; Ruhfel et al., 2011; Wurdack and Davis, 2009). Three tribes are recognized within Hypericaceae: the tropical tribes Vismieae Choisy (Vismia Vand., Harungana Lamarck and Psorospermum Spach) and Cratoxyleae Bentham \& J.D. Hooker (Cratoxylum Blume, Eliea Cambess.), and the widespread tribe Hypericeae Choisy, including the genera Triadenum Raf., Thornea Breedlove \& McClintock, Santomasia N. Robson, Lianthus N. Robson, and Hypericum (Fig. 1, inset). Yet, relationships among genera remain unclear (see below).

Hypericum is one of few large genera with an almost complete taxonomic treatment. Robson (Robson, 1977, 1981, 1985, 1987, 1990, 1996, 2001, 2002, 2006, 2010a, 2010b, 2012) published a series of monographs in which he described numerous species and defined the main diagnostic characters for the taxonomy of the genus. Robson divided the genus into 36 sections (see Nürk and Blattner (2010) for a synthesis of Robson's classification), and proposed relationships between sections based on the evolutionary direction of certain traits, such as the habit form, presence of dark glands, corolla shape, or the number of stamen fascicles. Based on Robson's study, Nürk and Blattner (2010) carried out the first morphological cladistic analysis of the genus, and concluded that some of these diagnostic characters were under convergent evolution. They also found discrepancies with Robson's sectional classification, and suggested the inclusion of the monotypic genus Santomasia within Hypericum.

In contrast to morphological studies, work at the molecular level has been slower in Hypericum, probably due to the difficulty to work with such a large and cosmopolitan genus. Ruhfel et al. (2011) analyzed relationships beyond the genus level in the clusioid clade and concluded that Hypericum is not monophyletic, with genera Santomasia, Triadenum, and Thornea embedded within. However, their study included only 21 Hypericum species, so little could be inferred in terms of infra-generic relationships. Other molecular studies focusing on interspecific relationships in Hypericum were too limited in both taxonomic and geographic coverage (Crockett et al., 2004; Heenan, 2008; Park and Kim, 2004; Pilepić et al., 2011). Just recently, Nürk et al. (2012) published the first deep-sampled molecular phylogeny for the genus including ca. $40 \%$ of the species diversity. They confirmed the inclusion of Triadenum within Hypericum, but, contrary to Ruhfel et al. (2011), recovered Thornea as the sister group of Hypericum. They also reconstructed ancestral states for some diagnostic characters, confirming many of Nürk and Blattner's (2010) conclusions. All the above-mentioned species-level phylogenies were based solely on ribosomal nuclear internal transcribed spacer. It is well known, that phylogenies based on ITS alone can be problematic because this marker displays a complex evolutionary behavior owing to concerted evolution among its multiple copies (Álvarez and Wendel, 2003). Also, biological processes such as hybridization, duplication, introgression, or incomplete lineage sorting may obscure the correlation between gene trees and the species tree. Thus, additional inclusion of plastid genes is desirable when reconstructing evolutionary relationships among species (Doyle, 1992).

Hypericum is unique within the clusioid clade in its variable habit form and mainly temperate distribution (most of the other genera are woody elements of tropical forests). The largest diversity of the genus is found in temperate areas of the Northern Hemisphere, 
Eurasia and North America, but some sections have reached highaltitude areas in the tropical regions, such as the South American Andes, where they exhibit some remarkable radiations, i.e., the 88 species in section Brathys (Robson, 2012). In Africa, the genus exhibits an interesting biogeographic disjunction, in which related species are distributed along the margins of the continent (e.g., Macaronesia, the Eastern African Mountains, and South Africa) as well as in Madagascar, in what has been called the "Rand Flora pattern" (Sanmartín et al., 2010) (see Fig. 1). Interestingly, Robson (1981) placed the origin of Hypericum in Africa and hypothesized that the character states exhibited by the Afromontane species, such as the treelet habit or presence of dark glands, were the "ancestral" states for the genus. He thought that the genus was very old and probably originated before direct land connections between Africa and the other parts of Gondwanaland broke off in the Mesozoic. This hypothesis, however, is at odds with a recent revision of the fossil record of Hypericum (Meseguer and Sanmartín, 2012), and with molecular estimates of divergence times in Malpighiales (Davis et al., 2005), dating the split between Hypericaceae and its sister family Podostemaceae in the Early Paleocene. Meseguer and Sanmartín (2012) placed the oldest fossil evidence of Hypericum in the Late Eocene of West Siberia, and suggested that the ancestors of the genus were part of the boreotropical forest belt that covered the Holarctic during the warm periods of the Early Tertiary (Tiffney, 1985a; Wolfe, 1975). Other studies (Nürk and Blattner, 2010; Nürk et al., 2012) have placed the origin of the genus in the Mediterranean Region based on the basal position of the Mediterranean clades. However, none of these hypotheses were tested within a formal biogeographic analysis.

In this study, we present the first species-level phylogeny of Hypericum based on both biparentally inherited nuclear DNA (nrDNA) and maternally inherited plastid DNA (cpDNA), and covering $40 \%$ of the described species and 33 out of the 36 proposed morphological sections. We use the full hierarchical Bayesian approach described in Huelsenbeck and Bollback (2001) and Ronquist (2004) to reconstruct the evolution of some of the most variable and taxonomically important characters in the genus. Finally, we applied a Bayesian discrete phylogeographic model (Lemey et al., 2009) in conjunction with relaxed clock dating and fossil evidence to estimate ancestral areas and the main migration events within the history of the genus.

\section{Materials and methods}

\subsection{Taxon sampling}

Sampling effort was aimed to cover morphological and geographic variation of the genus. We sampled ca. $40 \%$ of the species (186 species out of 496 ) and more than $90 \%$ of the sectional variation (33 sections out of 36). Our sampling is comparable with that of Nürk et al. (2012), which included 200 species, nearly $70 \%$ of them represented in this study. However, our final dataset comprises 3032 characters, a fourfold increase over similar studies at infrageneric level on Hypericum (Crockett et al., 2004; Park and Kim, 2004; Nürk et al., 2012), all of which were based on nuclear ITS. Missing sections were the East Mediterranean section Origanifolia with 13 species, and the monotypic sections Concinna (N. America) and Umbraculoides (Mexico). The missing species mostly belong to the large sections Brathys and Trigynobrathys from America, Ascyreia from Asia and Hirtella and Taenioarpium from Levant. We made a special effort to increase the sampling of African sections, which were usually poorly represented in previous phylogenetic studies of Hypericum.

We also included representatives of other Hypericaceae genera: Triadenum and Thornea, the latter only represented by GenBank ITS accessions, from tribe Hypericeae; Vismia and Harungana representing sister-tribe Vismieae, and genus Eliea from tribe Cratoxyleae. The latter was used as the most external outgroup to root the trees, following previous studies (Ruhfel et al., 2011; Wurdack and Davis, 2009). DNA data was obtained from fresh material collected in the field and preserved in silica gel, and from dry material preserved at several herbaria (Appendix A). GenBank accessions from previous studies of Hypericum, mostly ITS, were also included in the final dataset. Species names, voucher information and Genbank (NCBI dataset) accession numbers are shown in Appendix A.

\subsection{DNA extraction, amplification and sequencing}

Three plastid (trnS-trnG, psbA-trnH, trnL-trnF) and one nuclear (ITS) region were amplified using universal and newly designed primers. The intergenic spacers (IGS) trnS-trnG and psbA-trnH were amplified using primers from Hamilton (Hamilton, 1999). Additional degenerate internal primers were designed for trnS-trnG: trnSG-A (5'-ACT GCT TCG ACT MAA TTT MG-3') and trnSG-B (5'AGG ATT MGG ATT GMT CTT GTT TC-3') using the software OligoCalc (Kibbe, 2007). We amplified the $t r n L-t r n F$ region using primers c-f from Taberlet et al. (1991). The ITS region was amplified using the universal primers ITS4 and ITS1a (Aguilar et al., 1999; White et al., 1990). For some species that were difficult to amplify, we used also the internal primers ITS2 and ITS3 (White et al., 1990). DNA was extracted from leaf tissue samples using the QIAGEN DNeasy plant kit (Qiagen, Hilden, Germany) at the laboratories of the Real Jardín Botánico-CSIC (Madrid, Spain), and following the manufacturer's protocol. Amplification was achieved in a $25 \mu \mathrm{l}$ reaction volume using the PCR mix BioMix (Bioline, Germany). The PCR cycling conditions were as follows: $95^{\circ} \mathrm{C}$ for $5 \mathrm{~min}, 35 \mathrm{cy}-$ cles of $\left[94^{\circ} \mathrm{C}\right.$ for $30 \mathrm{~s}, 52-56{ }^{\circ} \mathrm{C}$ for $1 \mathrm{~min}, 72{ }^{\circ} \mathrm{C}$ for $1.5 \mathrm{~min}$ ] and a final extension step of $10 \mathrm{~min}$ at $72{ }^{\circ} \mathrm{C}$. PCR products were checked on $1 \%$ agarose gels and sequencing was performed at Macrogen, Inc. (Seoul, South Korea), using the initial PCR primers. Amplified products were purified using the Qiagen PCR Purification Kit. We occasionally got multiple fragments of different lengths, especially in $p s b A-t r n H$, which were directly isolated from the gel using the Zymoclean Gel DNA Recovery kit (California, USA).

In most cases we obtained unambiguous sequences, but some ITS sequences showed more than one polymorphic site (e.g., clear double peaks in both sequence strands). To screen for possible variants, PCR products were cloned using the CopyControl cDNA, Gene and PCR Cloning Kit (Epicentre, Madison, USA), according with the manufacturer's manual. Fifteen positive colonies were selected and amplified using the universal primers T7 and pCC1/pEpiFOS RP-2 reverse sequencing primer. No sequences with $>5 \%$ divergences were found among the clones, so we included these sequences in the final dataset.

\subsection{Phylogenetic methods}

DNA sequences were edited using Sequencher 4.7 (Gene Codes, Ann Arbor, MI). High levels of sequence variation, especially in relation to the presence of indels or gaps, were found in all markers, in agreement with other studies of malpighiales (Davis et al., 2005; Wurdack and Davis, 2009). Thus, sequence alignment was difficult and we followed a three-stage approach. First, sequences were aligned using the online version of MAFFT v.6 (Katoh and Toh, 2008), with the default option L-INS-I (Katoh et al., 2002; Katoh and Toh, 2008), and visually adjusted using the software Se-Al v2.0a11 Carbon (Rambaut, 2002). Second, the software Gblocks v. 0.91b (Castresana, 2000) was used to identify and remove ambiguously aligned regions such as large segments of non-conserved positions or with a large density of gaps. We used this approach only for the ITS marker, because alternative analyses with or 
without Gblocks showed that including these ambiguous regions in the chloroplast alignments yielded stronger statistical support for several clades. Third, "informative" gaps were coded as binary characters using the "simple gap" coding (Simmons and Ochoterena, 2000) implemented in the software SeqState version 1.4.1 (Müller, 2005). Although gaps are a potential source of information in phylogenetic analysis, they can be difficult to align and might artificially increase the homoplasy in the dataset. We only coded gaps as informative characters if they could be unambiguously aligned across species, such as positionally homologous deletions embedded within an otherwise conserved segment. This was the case of the trnS-trnG and trnL-trnF markers, where gaps grouped clades that were also supported by standard substitution characters. Conversely, gaps were coded as missing data (non-informative) in the psbA-trnH dataset - or removed with Gblocks prior to analysis in ITS - because they could not be unambiguously aligned and including them lowered general clade support values.

\subsection{Phylogenetic analysis}

\subsubsection{Single-marker and combined analyses}

We used Bayesian inference (BI) implemented in MrBayes v3.2 (Ronquist et al., 2012) to infer phylogenetic relationships in Hypericum. Substitution models for each gene were selected based on the Akaike Information Criterion (Akaike, 1973) implemented in MrModeltest 2.3 (Nylander, 2004). The GTR model with rate variation among sites following a gamma distribution $(G T R+G)$ was the best model for the chloroplast markers, and the same model but with a proportion of invariable sites $(G T R+G+I)$ was selected for the ITS marker. For the gap partition in trnS-trnG and trnL-trnF, we applied a restriction site model (F81) with "lset coding = variable" to accommodate the ascertainment bias. Two independent runs of three Metropolis-coupled chains each were run for 10-20 million generations, sampling every 1000 generations. Mixing and convergence among chains were assessed using the standard deviation of split frequencies in MrBayes and the effective sampling size criterion (values $>200$ ) in Tracer v1.6 (Rambaut and Drummond, 2009). We also used the online tool AWTY (Nylander et al., 2008) to monitor cumulative posterior probabilities and among-run variability of split frequencies to ensure that all chains have reached the same stationary phase. After discarding the first 1-2 million generations (10-20\% of samples) as "burn-in", the remaining samples from the independent runs (approx. 18,00016,000 ) were summarized into a $50 \%$ majority rule consensus tree with clade posterior probabilities to approximate the posterior distribution of the phylogeny. To speed up convergence, we estimated a maximum likelihood tree with the fast software RAxML v.7.2.8 online version (Stamatakis et al., 2008), and employed this tree as the starting value ("starting tree") for the tree parameter (tau) and the branch length parameter (V) with the MrBayes v3.2 commands: "startvals tau = mystarttree $V=$ mystarttree". To avoid using the same starting tree in the two independent runs, which makes it more difficult to detect convergence problems, we introduced random perturbations in the ML tree with the command "mcmcp nperts $=0.1$ "; we then used these slightly perturbed versions of the original tree as starting trees for the two runs. Additionally, we used the program GARLI v2.0 (Zwickl, 2006), which performs highly efficient likelihood searches, to estimate the phylogeny under the maximum likelihood criterion, using the evolutionary model selected by MrModelTest, and repeating the analysis twice starting from different random trees. Clade support was assessed by non-parametric bootstrapping using 500 replicates in GARLI.

Before concatenating the different genes into a single dataset, we assessed congruence by running analyses on each individual marker, and comparing the resulting consensus trees for cases of "well-supported conflicting clades", i.e., clades that are significantly supported (>95 Bayesian posterior probability) in one gene tree but not in the consensus trees of the other markers. We also tested for substitutional saturation in each marker by plotting the uncorrected pairwise sequence distances ("p") against ML distances derived in PAUP* v4.0b10 (Swofford, 2002) under the selected nucleotide model, and checking for deviation from linearity of plots. Since no significant incongruence was found among the plastid markers (but see below), we combined them into a single dataset using the program Phyutility v2.2 (Smith and Dunn, 2008), which was analyzed in MrBayes under the same settings as above. The ITS marker was analyzed separately to compare topologies between the nuclear and plastid genomes and to avoid artifacts derived from combining markers with different levels of heterogeneity in mutation rates.

\subsubsection{Missing data and partitioning strategy}

Sensitivity analyses were carried out to evaluate the effect of missing data and different partitioning strategies in the combined three-marker cpDNA dataset. Missing data, due to failure to amplify some markers for certain specimens, may introduce problems in Bayesian phylogenetic inference (Lemmon et al., 2009; Simmons, 2012) but see (Wiens, 2006; Wiens and Morrill, 2011) for a different view). To evaluate the effect of the missing data in our cpDNA dataset, we run Bayesian and ML analyses using the same parameter settings as above on three different concatenate matrices: (a) "No-missing": including only those specimens that were represented in all three chloroplast markers; (b) "Two-markers”: including only those specimens sequenced for at least two markers; (c) "All-specimens": including all sequenced specimens (approximately $53 \%$ of specimens missing at least one marker). We then compared the resulting trees from these analyses in terms of tree topology, clade support, and level of resolution, i.e., number and percentage of resolved nodes over the total number of nodes for a tree of this size. Results showed that the presence of missing data decreased the level of resolution in the resulting phylogeny: "Nomissing”: 79 resolved clades (87\% over total number); “Two-markers" 112 (77\%); "All-specimens": 119 (62\%). The overall topology and major clades were recovered by all three datasets. Because the "All-specimens" dataset contains more data, phylogenetic discussion will be based on this. However, clade support and resolution are lower than in the "Two-markers" dataset, so we used the latter for the reconstruction of ancestral states and the biogeographic-dating analysis.

We also performed a sensitivity analysis to evaluate the impact of different partitioning strategies. The benefits of creating partitions - assigning an independent evolutionary model to each molecular marker in a multi-gene Bayesian analysis - have been discussed in several studies (Marshall, 2010; Marshall et al., 2006; Nylander et al., 2004). Partitioning, especially if allowing the overall mutation rate to differ among markers, can improve the fit to the data and decrease the variance, which results in higher clade support values and more accurate phylogenetic relationships (Marshall et al., 2006; Nylander et al., 2004). Yet, recent studies (Brown et al., 2010; Marshall, 2010) have warned about the dangers of a partitioned multi-gene dataset when the rate of mutation differs highly among partitions. When data from independent partitions evolve at very different rates, the analysis can get trapped in regions of low posterior density and "overly" long trees, where branch lengths are severely overestimated. One solution to this problem is to increase the value of the $\lambda$ parameter that controls the exponential prior on branch lengths $(1 / \lambda)$, which has the effect of pushing up the exponential prior more tightly around small branches (Brown et al., 2010; Marshall, 2010; Marshall et al., 2006). To test this effect in our concatenate cpDNA "All-specimens" dataset, we run Bayesian analyses with three different 
partitioning strategies: (1) "All-unpartitioned" dataset, in which a single substitution model was applied to all sites; (2) "All-partitioned uncorrected" dataset in which "rate multipliers" $m_{1}, m_{2} \ldots m_{n}$ were estimated per partition to accommodate rate variation ("prset ratepr $=$ variable") but the branch length prior was assigned the default value $(\lambda=10,1 / \lambda=0.1)$; and 3$)$ "All-partitioned corrected" dataset accommodating among-partition rate variation ("prset ratepr $=$ variable"), but lowering the value of the exponential prior $(\lambda=100,1 / \lambda=0.01)$ using the command "prset brlenspr $=$ Unconstrained:Exp(100)". Bayes Factors, based on the harmonic mean of the two runs (Kass and Raftery, 1995), were used to compare the marginal likelihood and fit to the data of each partitioning strategy.

\subsection{Ancestral state reconstruction}

Bayesian ancestral state reconstructions (ASRs) were performed in MrBayes v 3.2 on the concatenate "Two-markers" chloroplast dataset using the full hierarchical Bayesian approach, i.e., integrating out uncertainty concerning tree topology and other model parameters (Huelsenbeck and Bollback, 2001; Ronquist, 2004). We did not use the ITS dataset because higher rate heterogeneity and recombination in nuclear markers may hinder the estimation of evolutionary rates and associated branch lengths (Álvarez and Wendel, 2003). This makes ITS less appropriate for inferring ancestral states and lineage divergence times, especially if as in Hypericum there are changes in life history traits: e.g., shifts between woody/perennial and herbaceous habits (Kay et al., 2006; Litsios and Salamin, 2012). We reconstructed evolutionary patterns in seven morphological diagnostic traits: habit form, presence of dark glands, number of fasciclodes (vestigial fascicles), ornamentation of seed testa, shape of flower corolla, and number and degree of fusion of stamen fascicles; see Supplementary information (SI) Appendix for a description of characters. Some species were coded as polymorphic for certain characters, e.g., $H$. revolutum exhibits both the cyathiform and stellate corollas (Fig. 4), which is interpreted as ambiguity in Bayesian ASR. We reconstructed ancestral states in eight lineages representing the main clades recovered in the phylogenetic analyses, which also received high clade support (>95\% except for clade C). Each morphological character was added to the end of the molecular matrix and modeled according to the Mk1 model of Lewis (Lewis, 2001) (standard discrete model), with its own partition-specific rate multiplier. We analyzed each matrix (plastid dataset +1 character) separately to minimize the influence of morphology in the estimation of phylogenetic relationships. All other settings were identical to those used above in the Bayesian inference of the phylogeny (e.g., by-gene partitioned analysis with corrected lambda prior, ML starting tree).

\subsection{Molecular dating}

Absolute lineage divergence times in Hypericum were estimated in BEAST (Drummond and Rambaut, 2007) using a Bayesian relaxed clock-model. The chloroplast "Two-markers" dataset was used for the analysis with the following settings: a by-gene partitioned dataset with GTR+G as substitution model, Yule tree prior, and uncorrelated lognormal relaxed clock (UCLD). Bayes Factors were used before to discriminate between different model clocks (strict/relaxed) and partitioning strategies (partitioned/unpartitioned). Topological constraints were enforced to include prior phylogenetic knowledge in the analysis. In particular, initial BEAST runs did not recover the sister group relationship between $H$. elodes and $H$. aegypticum with the rest of Hypericum (supported by Nürk et al. (2012) and our MrBayes analyses), or the position of Eliea as sister to Vismieae-Hypericeae, which is also supported by Rufhel et al.'s (2011) clusioid clade phylogeny. These relationships were enforced in all subsequent BEAST analyses. To avoid conflict between the starting tree and the topological priors in the analysis, we used the "allcompat" tree from the Bayesian analysis, with branch lengths calibrated by Non-Parametric Rate Smoothing (NPRS) (Sanderson, 1997) using the software TreeEdit v.1.0a10 (Rambaut and Charleston, 2001) and a fixed age for the root node calibration (see below). Two replicate MCMC searches of 30 million generations each were run under these settings and their results pooled using the software LogCombiner v. 1.7.2 (after removing $25 \%$ samples as burn-in). We used Tracer 1.6 to determine stationarity of the Markov chain and to verify that all parameters have effective sampling sizes (ESSs) $>200$. TreeAnnotator v1.4.8 (Drummond and Rambaut, 2007) and FigTree v. 1.3.1 (Drummond and Rambaut, 2007), respectively, were used to generate and visualize the resulting maximum clade credibility (MCC) tree.

We used two external calibration points based on fossil evidence to obtain absolute divergence times:

(a) The root node, the crown age of Hypericaceae or the split between Eliea and the rest of the tree, was constrained according to Ruhfel (2011)). He dated a molecular phylogeny of the clusioid clade (Ruhfel et al., 2011) using two fossil calibration points: the Upper Cretaceous macrofossil Palaeoclusia chevalieri and the Eocene pollen fossil Pachydermites diederexii. The fossil Pachydermites is placed with confidence as the most recent common ancestor (MRCA) of Pentadesma and Symphonia (Ruhfel, 2011). However, the phylogenetic position of Palaeoclusia is still controversial. Ruhfel (2011) conducted two independent analyses with different positions of the fossil in the phylogeny: as the stem age of the clusioid clade (OC position: MRCA of Ochnaceae s.l. and the clusioid clade), and as the stem node of the Clusiaceae family (BC position: MRCA of Bonnetiaceae and Clusiacae s.s.). Depending on the position of Palaeoclusia, he obtained a crown age for Hypericaceae between 58.9 and 71.5 Ma (OC and $\mathrm{BC}$, respectively). To integrate this uncertainty in our analysis, we assigned a normal prior to the crown age of Hypericaceae, with mean $65.2 \mathrm{Ma}$ (the mean of the BC and OC ages) and a std. of 11 to span the entire confidence interval (47.9-86.4 Ma) obtained by Ruhfel (2011)).

(b) To constrain the crown age of Hypericum, we used the fossil seed Hypericum antiquum, from the Late Eocene of West Siberia (Arbuzova, 2005), considered the oldest fossil remain of the genus (Meseguer and Sanmartín, 2012) (see SI Appendix for a discussion on the phylogenetic position of the fossil in our phylogeny). We used a lognormal prior to reflect the uncertainty in the fossil calibration (as recommended by Ho and Phillips, 2009), with the uppermost limit of the time interval (Priabonian) as a minimum hard bound (offset $=33.9 \mathrm{Ma})$ and a standard deviation $(\mathrm{Std}=0.7)$ that includes the entire geological interval (33.9-37.2 Ma) (Walker and Geissman, 2009).

\subsection{Biogeographic analysis}

We inferred posterior estimates of ancestral ranges for the main lineages in the phylogeny in two different ways. First, we use Bayesian ASR and a similar approach to the morphological reconstruction above. Geographic distribution was coded as a multistate character and added to the "Two-marker" dataset as a standard morphological partition using the morphological discrete Mk1 model. Seven discrete areas were defined according to the paleogeographic history of the continents (see Fig. 5 and SI-Appendix): eastern Palearctic (EP), western Palearctic (WP), Nearctic $(\mathrm{Ne})$, Neotropical (Nt), Afrotropical (AF), Oceania (OC), and IranoTuranian-Himalayan region (ITH). Ancestral ranges were estimated for the eight clades described above. 
Second, we used the Bayesian discrete phylogeographic approach of Lemey et al. (2009), implemented in BEAST v.1.6.2, to infer ancestral ranges and trace the history of geographic movement across regions in Hypericum. In the Bayesian ASR, branch lengths are measured as expected number of substitutions per site per unit of time, as in a phylogram. Although this is appropriate for inferring the rate of morphological evolution, especially if there are associated changes in life history traits (Litsios and Salamin, 2012), time-calibrated branch lengths measured as units of absolute time (as in a chronogram) are probably more interesting for inferring biogeographic history because dispersal barriers arose and fell through time (Ree and Sanmartín, 2009). Lemey et al.'s (2009) biogeographic method allows jointly estimating the posterior distribution of topologies, divergence times, and ancestral ranges given molecular data and the geographic location of each species. The model is very similar to the Bayesian Island Biogeography (BIB) model described in Sanmartin et al. (2008) in that movement between geographic areas is modeled as a discretestate continuous-time Markov chain (CTMC) with transition states (ancestral ranges) limited to single areas (Ronquist and Sanmartín, 2011). Dispersal rates between areas and ancestral ranges at nodes are estimated using MCMC Bayesian inference (Lemey et al., 2009). We run two replicate searches of 30 million generations, using uninformative priors for dispersal rates instead of constraining them by geographic distance (Lemey et al., 2009), since this changed over time with continental movement; the remaining BEAST settings were identical to the ones described in "Molecular dating". The discrete CTMC model implemented in BEAST v.1.6 can only handle single-area terminals. Because we used such all-encompassing areas (i.e., continents or major continental landmasses), most terminals ended up being endemic to a single operational area (Nearctic, Africa, etc.). As a result, there were only seven widespread species in our dataset, i.e., occurring in more than one region (SI-Appendix). We coded those widespread terminals as occurring in the area where the voucher was collected. However, this could introduce bias in the analysis if the sampling was not homogeneous among regions or the terminals represent larger clades with a widespread distribution such as outgroups. To examine the influence of forcing widespread terminals to occur in single areas, we carried out a second analysis in which these terminals were coded for the alternative area, for example, Vismia was coded as South American instead of African (see Fig. 5 and SI-Appendix).

\section{Results}

\subsection{DNA sequence variation}

Table 1 summarizes the main characteristics of the genomic regions studied. In total, 669 sequences were analyzed, of which 587 were generated in this study. The ITS dataset yielded a matrix of
520 characters and 252 specimens. The combined matrix of chloroplast regions ("All-specimens") has 3072 aligned positions and 192 taxa. The saturation plots for the individual markers show a strong fit to a linear regression, although ITS and $p s b A-t r n H$ present the lowest correlation and their saturation plots indicate slight levels of substitutional saturation at the deeper divergences (see Table 1 and SI Fig. 1). All data matrices can be obtained on request from the corresponding author.

\subsection{Topological congruence and sensitivity analysis}

Figs. 2 and 3 show the Bayesian consensus trees with BI and bootstrap values obtained with GARLI for ITS and the combined "All-specimens" cpDNA dataset, respectively; consensus trees for each individual chloroplast marker, psbA-trnH, trnS-trnG, trnL-trnF, are shown in SI Fig. 2. Overall, there was general topological congruence among plastid markers, with the exception of some cases of well-supported incongruence affecting $p s b A-t r n H$ (SI Fig. 2). One conflict concerns several species from sections Hypericum, Adenosepalum and Crossophyllum that form a clade in psbA-trnH, but are scattered along the tree in the other cpDNA markers (SI Fig. 2 and Appendix A). Another relates to the placement of several not closely related specimens (e.g. H. balearicum_C40, H. coris_C23, Triadenum petiolatum_C16, $\mathrm{H}$. synstylum_C11) that occupy different positions in psbA-trnH than in all other markers (SI Fig. 2 and Appendix A). We discarded human error by repeating the sequencing of these specimens, and ensuring that they fall in the same position than in the first analysis. Many of these relationships are not supported by the traditional classification based on morphological characters (Robson, 1977) and do not appear in the ITS tree. Moreover, analyzing the combined plastid dataset with (SI Fig. 3) and without these incongruent sequences (Fig. 3) did not affect the overall topology of the tree, which recovered the same major groupings. Excluding psbA-trnH altogether - analyzing a combined matrix with trnS-trnG and trnL-trnF alone (SI Fig. 4) - also recovered a tree topology and groupings similar to Fig. 3, although including all three chloroplast markers increased significantly the support for many individual clades. Therefore, in discussing phylogenetic relationships in Hypericum, we used the complete (three markers) cpDNA dataset (Fig. 3) but excluding the problematic psbA-trnH sequences. Comparison between the combined cpDNA phylogeny (Fig. 3) and the ITS tree (Fig. 2) showed general levels of congruence, with all major clades supported by the two genomes. There was generally lower support in the ITS tree compared to the cpDNA tree, but there were a few cases of well-supported conflict (>95 pp) affecting species-level relationships. For example, the position of several species of the section Adenosepalum varies between the ITS and cpDNA trees; other species are assigned to different clades such as H. scouleri or H. monanthemum (Figs. 2 and 3 ).

Table 1

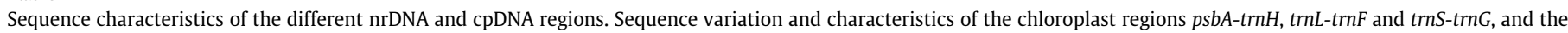
nuclear intergenic spacer ITS with and without the ambiguously aligned regions (excluded with the software Gblocks: "ITS Gblocks").

\begin{tabular}{|c|c|c|c|c|c|}
\hline & psbA-trnH & $\operatorname{trnL} L-t r n F$ & trnS-trnG & ITS (Gblocks) & ITS \\
\hline Number of accessions & 142 & 173 & 108 & 252 & 252 \\
\hline Aligned length & 1322 & 727 & 1023 & 520 & 783 \\
\hline Un-aligned length ${ }^{\mathrm{a}}$ & 525 & 604 & 670 & 518 & 710 \\
\hline Indel characters $(\%)$ & $797(60.3)$ & $123(17)$ & $353(30)$ & $2(0.38)$ & $73(9.3)$ \\
\hline Constant characters & 865 & 468 & 619 & 193 & 381 \\
\hline Parsimony-uninformative characters & 125 & 89 & 134 & 72 & 78 \\
\hline Parsimony-informative characters (\%) & $332(25.1)$ & $170(23.4)$ & $270(26.4)$ & $255(49)$ & $324(41.3)$ \\
\hline Mean sequence divergence ${ }^{\mathrm{b}}(\%)$ & $0.34-0(5.14)$ & $0.37-0(4.99)$ & $0.28-0(4.18)$ & $0.78-0(11.61)$ & $0.75-0(13.32)$ \\
\hline Saturation ( $r^{2}$ values) & 0.987 & 0.997 & 0.99 & 0.986 & 0.98 \\
\hline
\end{tabular}

a Total unaligned length per marker was obtained by averaging the length of 10 sequences per marker.

b Mean sequence divergence (\%) estimated in PAUP over the total number of sequences. 

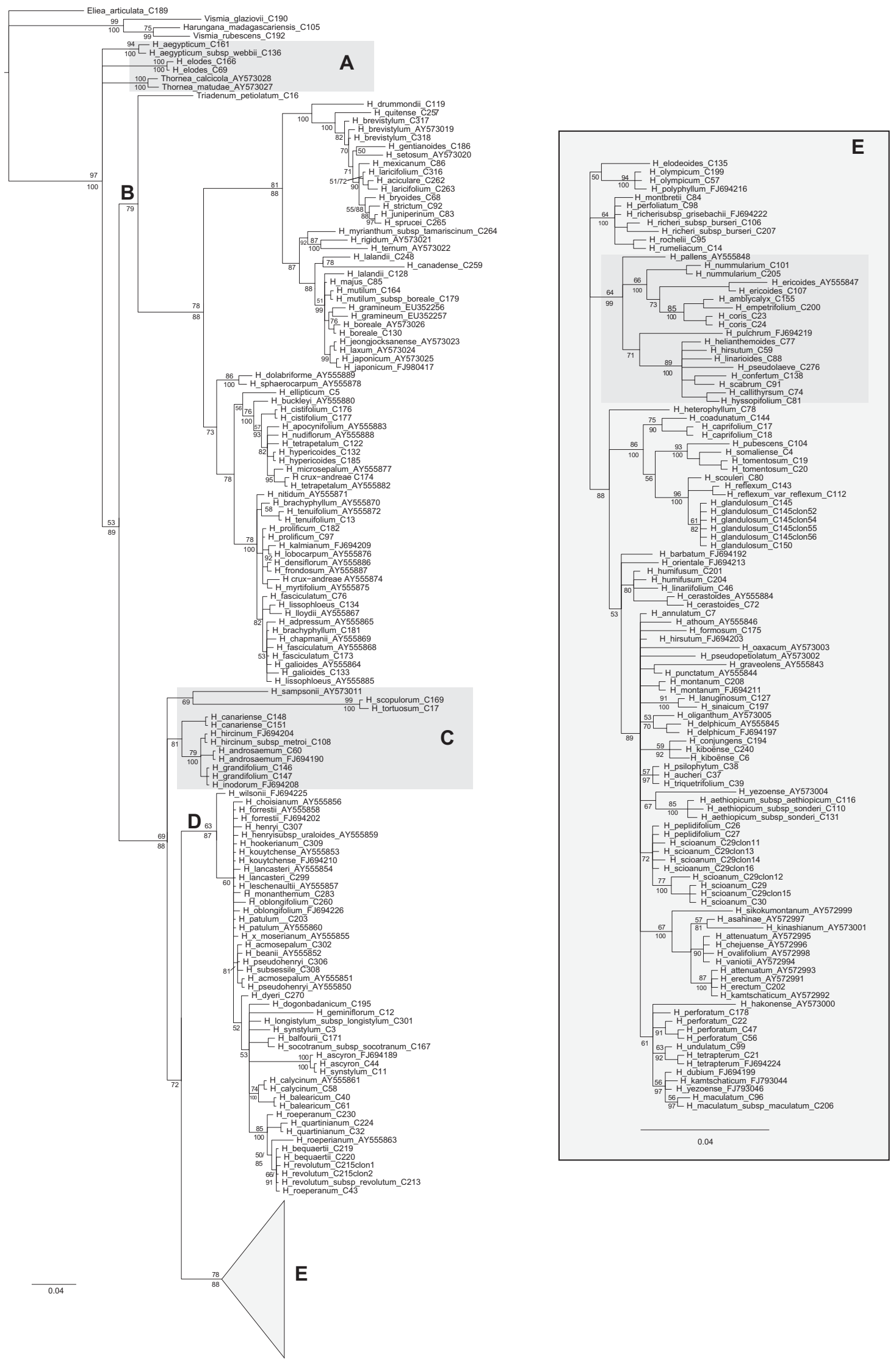

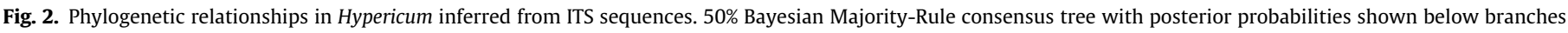

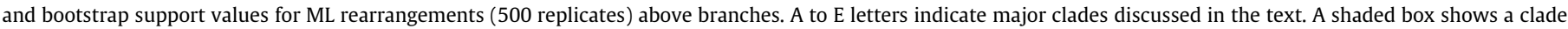
that is not well supported by the concatenate plastid dataset: "Hirtella-group". 


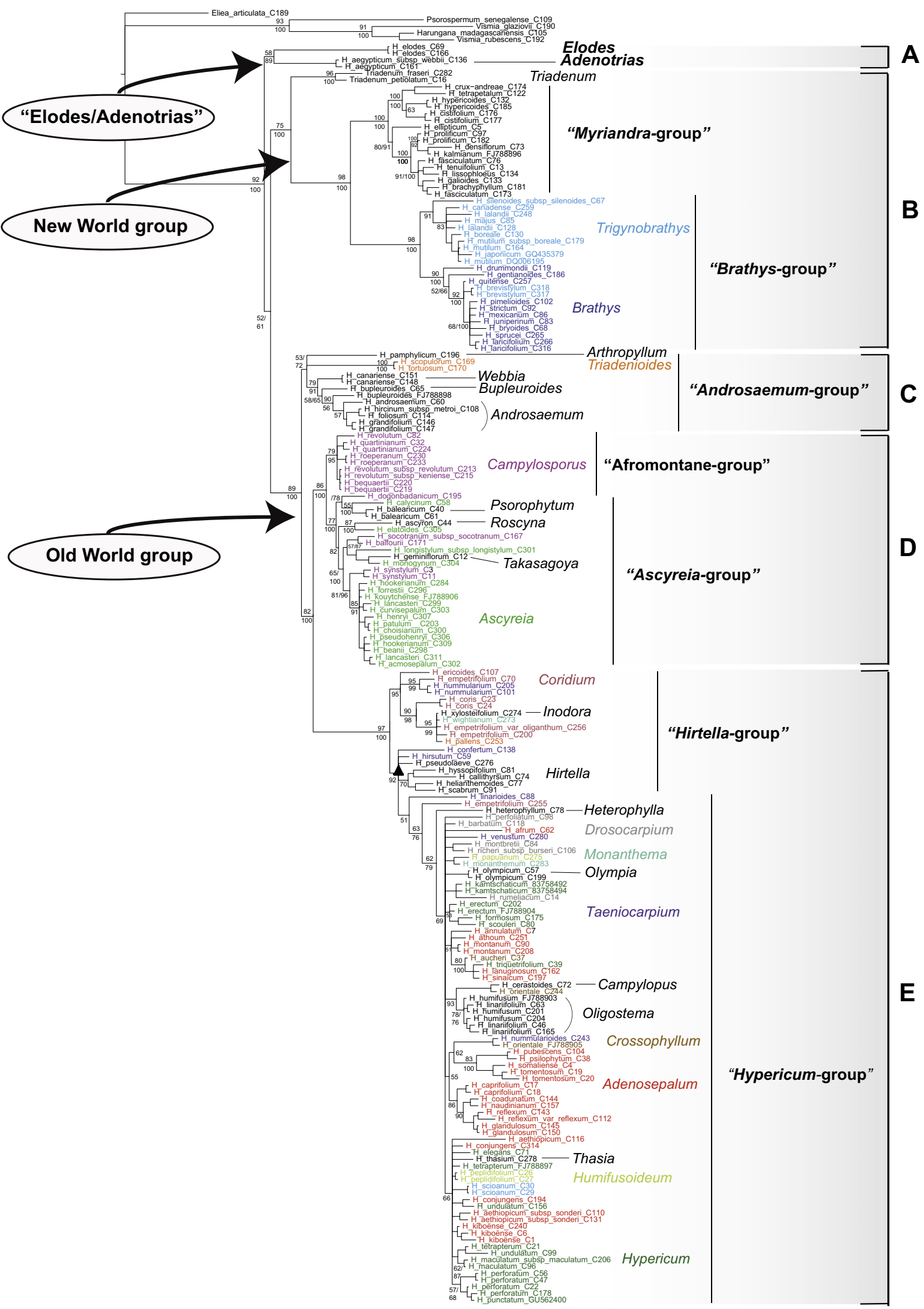

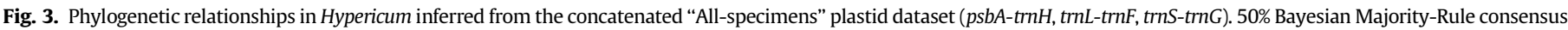

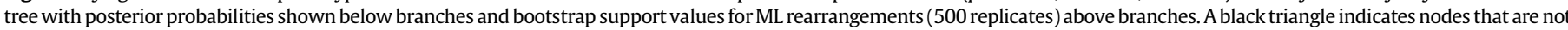

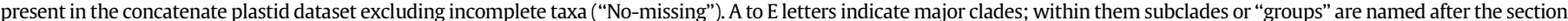

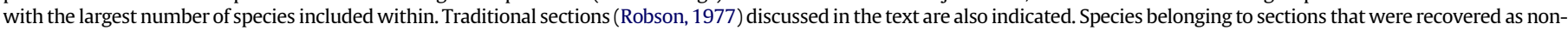
monophyletic have been highlited by different colours. (For interpretation of the references to colour in this figure legend, the reader is referred to the web version of this article.) 
Sensitivity analysis showed that the All-specimens "All-partitioned" datasets fit the data significantly better than the "Allunpartitioned" analysis (Table 2). Moreover, the "partitioned uncorrected" analysis with default branch length priors resulted in Bayesian consensus trees that were several orders of magnitude longer than the ML trees. In fact, the $95 \%$ credibility intervals of the Bayesian branch length estimates did not include the ML branch estimates, something that has been interpreted as evidence of inaccurate branch length estimates in MrBayes (Brown et al., 2010). By contrast, the "All-partitioned corrected" analysis with a lower exponential branch length prior resulted in very similar average branch length values between the BI and ML methods (Table 2). Interestingly, the same behavior was observed when we introduced the lambda correction in the single-gene analyses, resulting in average branch lengths that were shorter and more similar to the ML values (Table 2). The latter also resulted in a speed up in convergence among runs and better estimates for the among-site rate variation gamma parameter. One possible explanation is that considerable rate heterogeneity exist not only among partitions but also among sites within partitions, especially in ITS, where highly conserved regions are followed by long segments of variable, non-conserved positions. Therefore, all results presented here, are based on the corrected branch-length analyses ("All-partitioned corrected" strategy).

\subsection{Phylogenetic relationships}

The combined cpDNA and ITS phylogenies show Vismieae as sister group to Hypericum, which is recovered as non-monophyletic with genus Triadenum embedded within (Figs. 2 and 3 ).

Thornea is placed in a basal polytomy with the Elodes-Adenotrias lineage and the rest of Hypericum in the ITS tree (Fig. 2). Phylogenetic relationships within Hypericum are also congruent among markers (Figs 2 and 3), showing species from sections Elodes and Adenotrias ( $H$. elodes and $H$. aegypticum) as the sister-group of the remaining species, either forming a clade (A: Elodes-Adenotrias) in the cpDNA tree (Fig. 3) or a basal polytomy in the nuclear phylogeny (Fig. 2). Branching next is a sister-group relationship between a mainly New World clade (clade B) and an Old World clade (clades $\mathrm{C}-\mathrm{E}$ ). The New World lineage comprises species belonging to American sections Myriandra, Brathys, and Trigynobrathys, with genus Triadenum as their sister-group. The Old World lineage is divided into three major clades $\mathrm{C}, \mathrm{D}$, and $\mathrm{E}$, grouping species from Europe, Asia and Africa, but also from Oceania and the New World. Several monophyletic groups or subclades can be recognized within each of the major clades, which are also geographically structured but do not conform to the current sectional classification. These groups have been given the name of the section with the largest number of species included (e.g., "Ascyreia-group", Fig. 3).

The following sections were recovered as monophyletic in our analysis: Myriandra, Androsaemum, Oligostema, Webbia, Psorophytum, Campylopus, Bupleuroides, Heterophylla, Elodes, Thasia and Inodora, though the last seven are monotypic. Other sections were represented in the analysis by one specimen (e.g., Roscyna) or clade support was low (e.g., Hirtella), so monophyly could not be assessed. The remaining sections (e.g., Trigynobrathys, Campylosporus, Hypericum, Ascyreia) were inferred to be para- or polyphyletic (see Section 4, Table 3 ). In a few cases, con-specific specimens were not grouped together such as in species $H$. hookerianum, $H$. lancasteri, H. empetrifolium and $H$. aethiopicum in the cpDNA tree (Fig. 3), or $H$. lalandii and $H$. synstylum in the ITS tree (Fig. 2).

\subsection{Ancestral state reconstruction}

Fig. 4 shows Bayesian ASR results for seven diagnostic morphological characters. In general, uncertainty was low and most ancestral nodes were reconstructed with posterior estimates over 95\%. Our results suggest that the ancestor of Hypericum was a darkglandless shrub characterized by three fasciclodes, reticulate seed testa, stellate corolla and three stamen fascicles partially united forming a tube. The herbaceous habit seems to have evolved multiple times in the history of the group, and it is also reconstructed as the ancestral state of the largest clade $\mathrm{E}$ (Fig. 4); in contrast, the tree habit is an autapomorphy of the "Afromontane-group" in clade D. Dark glands have also evolved independently in clades A, D and E. Othe characters that evolved in parallel in different clades are the pseudo-tubular corollas in clade A and Triadenum within clade B, and the presence of five stamen fascicles in clades D and B (with the exception of Triadenum, Fig. 4).

\subsection{Molecular dating}

The crown age of Hypericaceae was estimated at 53.8 Ma with a very broad confidence interval (CI 43 - $66 \mathrm{Ma}$; SI Appendix). Divergence between tribes Hypericeae (=Hypericum) and Vismieae occurred during the Early Eocene (49.9 Ma; CI 41 - $60 \mathrm{Ma}$ ), while crown-group Hypericum is dated as Late Eocene, $34.9 \mathrm{Ma}$ (CI 34 - $37 \mathrm{Ma}$ ). Divergence between the New World and Old World groups is dated in the Eocene-Oligocene boundary (33.7 Ma; CI 30 - $37 \mathrm{Ma}$ ), whereas divergence within the three major clades is dated as Early Oligocene (SI Appendix). In general, confidence intervals were small, except for some early divergences, such as the root node, the split of tribe Vismieae, and the crown-age of Clade $A$.

Table 2

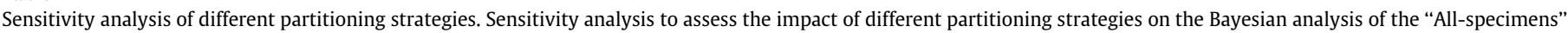

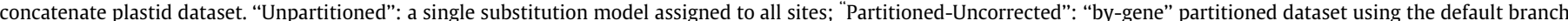

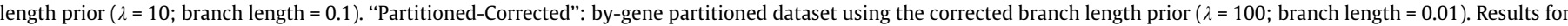

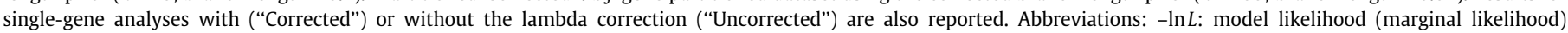

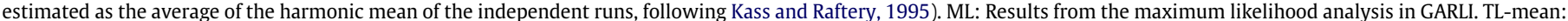
Mean of total tree length estimated over the two independent Bayesian runs. Lambda $(\lambda)$ : branch length prior parameter.

\begin{tabular}{|c|c|c|c|c|}
\hline $\begin{array}{l}\text { Bayesian } \\
\text { analysis }\end{array}$ & $\begin{array}{l}\text { - } \ln L \text { Unpartitioned } \\
\text { (TL mean) }\end{array}$ & $\begin{array}{l}\text { - } \ln L \text { Partitioned- } \\
\text { Uncorrected } \\
\text { (TL mean) }\end{array}$ & $\begin{array}{l}\text { - } \ln L \text { Partitioned- } \\
\text { Corrected } \\
\text { (TL mean) }\end{array}$ & $\begin{array}{l}-\ln L \text { ML analysis } \\
\text { (TL mean) }\end{array}$ \\
\hline "All-specimens" & -19330.09 (3.57) & $-19306.9(37.94)$ & $-19094.65(2.722)$ & $-18929.92(2.269)$ \\
\hline Single genes & $\begin{array}{l}-\ln L \text { Uncorrected } \\
\text { (TL mean) }\end{array}$ & & $\begin{array}{l}-\ln L \text { Corrected } \\
\text { (TL mean) }\end{array}$ & $\begin{array}{l}\text { - } \ln L \text { ML analysis } \\
\text { (TL mean) }\end{array}$ \\
\hline ITS & $-9615.51(58.489)$ & & $-9353.4(4.274)$ & $-8910.47(3.400)$ \\
\hline trnL-trnF & $-5915.90(30.461)$ & & $-5803.4(3.181)$ & $-4256.02(1.138)$ \\
\hline $\operatorname{trn} S-\operatorname{trn} G$ & -7607.17 (18.969) & & $-7503.3(1.871)$ & $-6163.75(1.644)$ \\
\hline psbA-trnH & $-8211.08(14.059)$ & & $-7936.4(2.817)$ & $-7668.11(2.845)$ \\
\hline
\end{tabular}



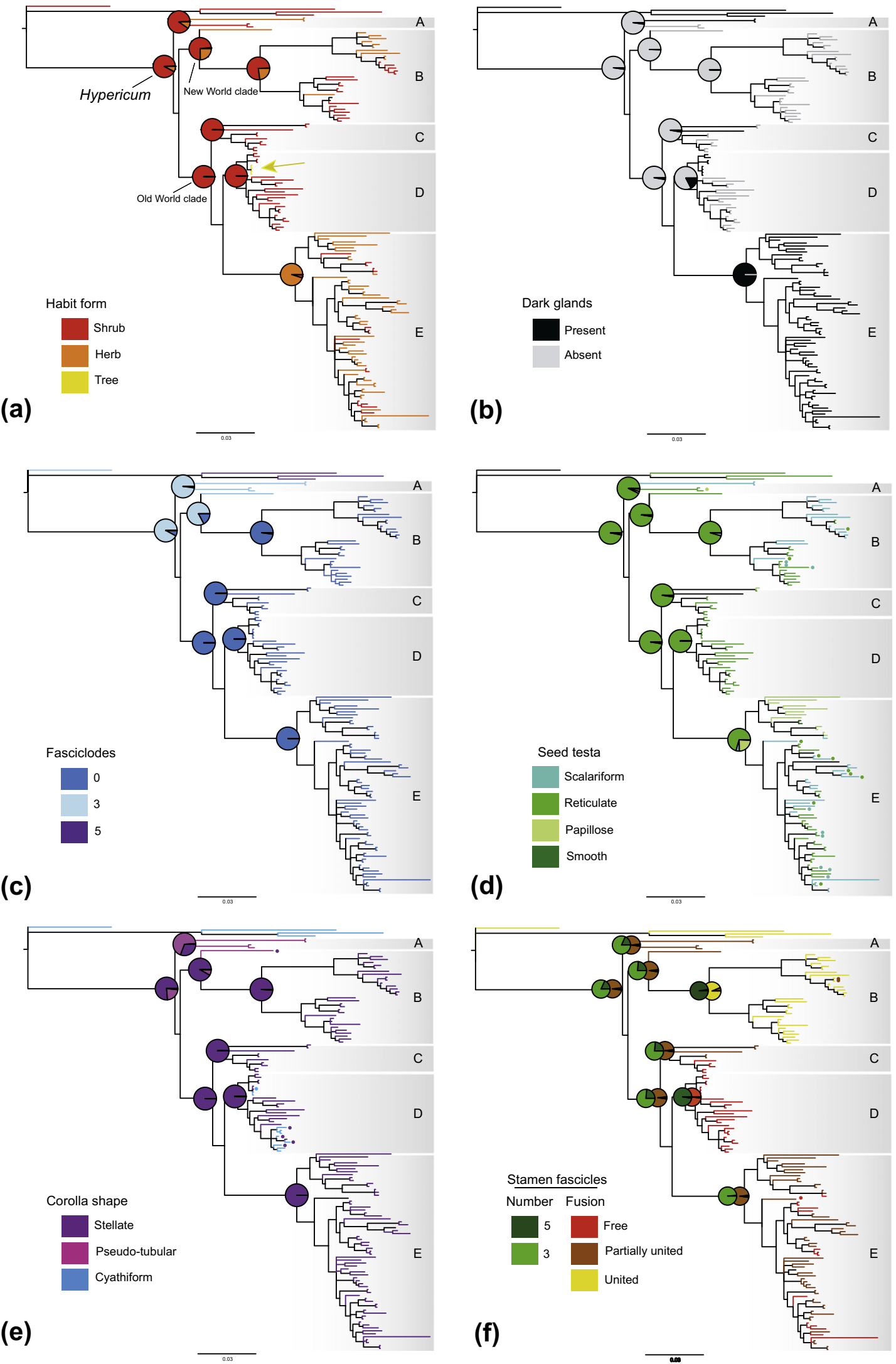

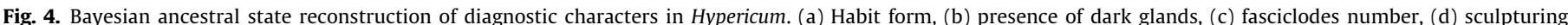

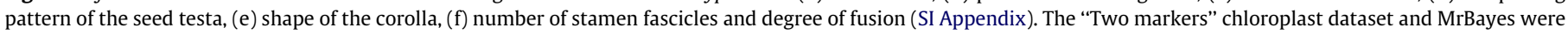

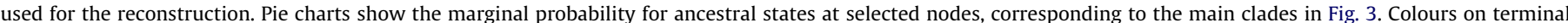

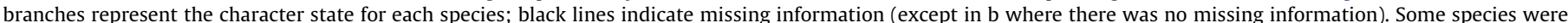

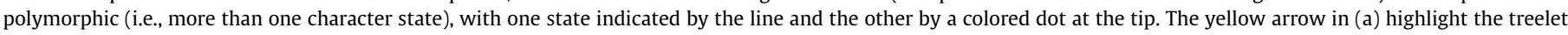
habit within clade D. 


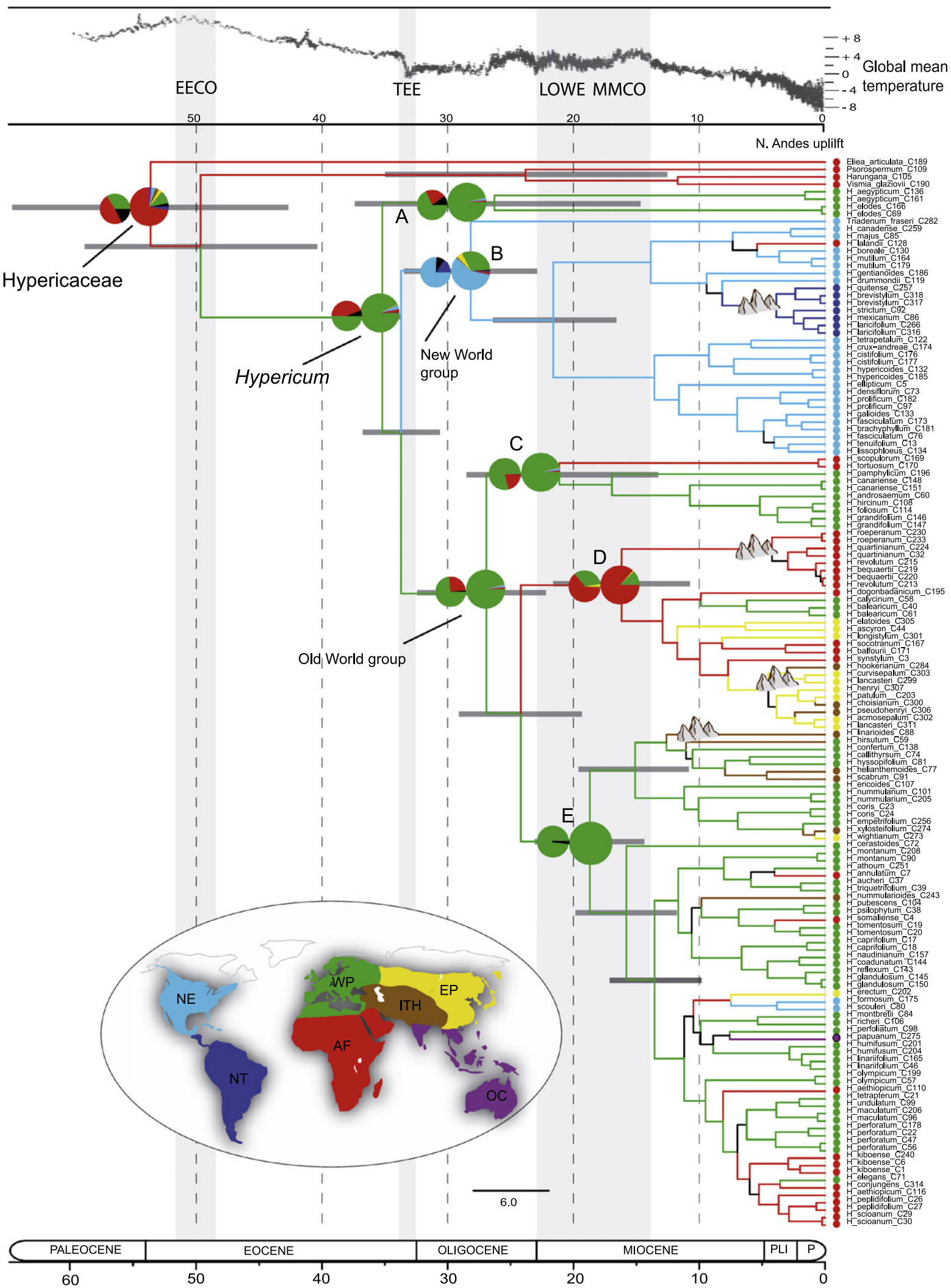

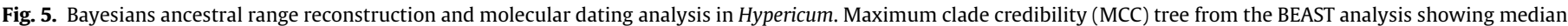

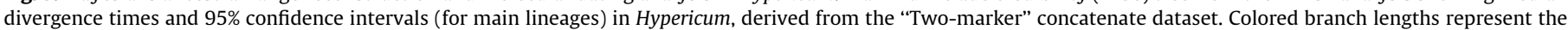

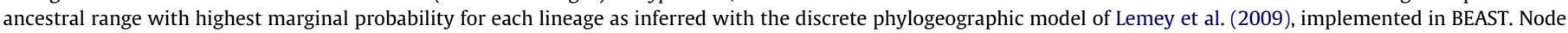

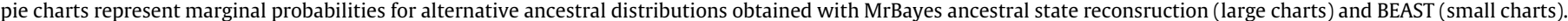

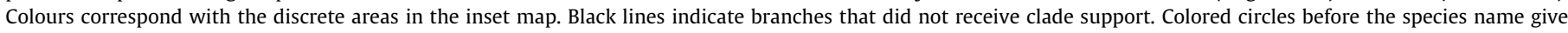

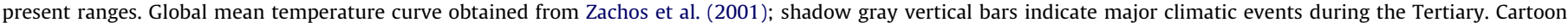

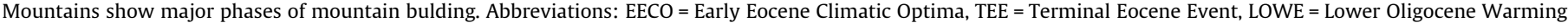

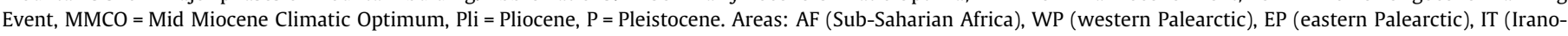
Turanian-Himalayan), OC (Oceania), NE (Nearctic), NT (Neotropic). 


\subsection{Biogeographic analysis}

Bayesian ASR of biogeographic ranges in MrBayes was also very decisive $(p p>90)$, showing Africa as the ancestral area of Hypericaceae, while the remaining ancestral nodes, including crown-group Hypericum, are inferred as originating in the Western Palearctic region (Fig. 5). The only exceptions are the MRCA of clade $\mathrm{B}$, which is reconstructed as Nearctic, and the MRCA of clade D, which is inferred as African (Fig. 5). The BEAST BIB reconstruction showed very similar results, but uncertainty was generally higher, which might be attributed to its higher model complexity, with more free parameters than in the standard discrete model used in MrBayes. Hypericaceae is reconstructed as African (marginal probability $p=0.48$ ), but other less supported scenarios included the Western Palearctic region $(p=0.34)$. The area of origin of Hypericum is most probably WP $(p=0.5)$, although Africa was again included among the most likely ancestral areas $(p=0.44)$. Several dispersal events back to Africa can be observed in the BEAST MCC reconstruction, most notably within Clade $C$ (in the lineage of $H$. tortuosum and H. scopulorum) and in Clade D (e.g., the "Afromontane-group"). Within Clade D, several dispersal events from Africa to the Western Palearctic, Eastern Palearctic, and Irano-Turanian-Himalayan region are reconstructed. Dispersal from the Nearctic region to the Neotropics is inferred within Clade B, concurrent with the Andean Brathys radiation. The most complex migration pattern is found in Clade E, with dispersal events from the Western Palearctic towards Africa, Irano-Turanian-Himalayan region, and the Eastern Palearctic but also trans-oceanic dispersal to the Nearctic and Oceania (Fig. 5). Coding the widespread terminals for the alternative area did not affect biogeographic reconstruction within Hypericum i.e., all nodes were reconstructed identically to those in Fig. 5. The only difference was the root of the tree and the ancestor of HypericeaeVismieae (crown node Hypericaceae), which were inferred as Western Palearctic, instead of African.

\section{Discussion}

\subsection{Congruence among markers}

Our ITS tree was generally congruent with the cpDNA phylogeny, recovering the same major clades and sectional relationships (Figs. 2 and 3). It also agrees well with Nürk et al.'s (2012) ITS phylogeny, showing the early divergent sections "Elodes-Adenotrias" as sister-group to a geographic dichotomy between a New World clade and an Old World clade. It is difficult to evaluate the congruence at distal levels, since the same taxa were not included in the two studies, and support is generally low for ITS phylogenies (Crockett et al., 2004; Nürk et al., 2012; Park and Kim, 2004; Pilepić et al., 2011). However, we found some cases of well-supported (>95 pp) incongruence between the ITS and the plastid trees in our study that affected low taxonomic levels. Several causes may explain incongruence between gene trees, ranging from hybridization, incomplete lineage sorting, positive selection, paralogy, or poor model choice. The ITS marker may also be affected by problems with homoplasy resulting from extensive sequence variation, compensatory base change, and indel accumulation (Álvarez and Wendel, 2003). Although some of these phenomena may be less relevant at long temporal scale, information from several genetic markers is advisable when inferring the species tree. Chloroplast markers are assumed to not been subject to the same recombination problems as multi-copy nuclear genes. In our case, the concatenated plastid phylogeny also shows better support levels and resolution than the ITS tree, which makes it more appropriate to solve species level relationships. In a multi-gene analysis, overall mutation rates might differ among partitions, and this can cause the overestimation of branch lengths in Bayesian partitioned inference (Brown et al., 2010). We found that this may affect also single-gene analyses when the rate of mutation differs greatly among sites or regions. Correction of the branch length prior helped recovering more realistic branch lengths, comparable with those inferred by ML. Interestingly, Nürk et al. (2012) reported ITS branch lengths that were orders of magnitude longer than our corrected branch lengths (Fig. 2) - but similar to our uncorrected ones (Table 2) - which might be explained by their posterior estimate of the phylogeny getting trapped in a region of overly long trees (Brown et al., 2010). Although this has generally no effects on the tree topology (Brown et al., 2010), it might be problematic if branch lengths are later used for inferring lineage divergence times.

Because the plastid genome is haploid and non-recombining, cpDNA markers are expected to show comparable evolutionary histories. Some studies, however, have shown that chloroplast dynamics are sometimes more complicated than assumed, and incongruence between chloroplast genes might reflect underlying biological processes (Medgyesy et al., 1985). Biparental inheritance of cpDNA has been reported in Hypericum (Greiner et al., 2011; Renner, 1934). These and other phenomena, such as chloroplast transfer, recombination, or complex mutational dynamics could lead to heteroplasmy (more than one type of organelle DNA within individual cells), which could explain the pattern of incongruence observed between psbA-trnH and the other markers (SI Fig. 2). In addition, Borsch and Quandt (Borsch and Quandt, 2009) described a very complex molecular structure including several structural mutations, ancient duplications, and inverted repeat regions in psbA-trnH. psbA-trnH is the marker in our study with the highest indel mutational rate relative to substitutions, and it exhibits higher levels of saturation than the other cpDNA markers (Table 1). Although we cannot discard the evolutionary processes mentioned above, it is more likely that homoplasy related to its short size (525 bp if gaps are excluded), high levels of variation, and difficulties in alignment due to its secondary structure, are responsible for the incongruities observed in the $p s b A-t r n H$ gene tree.

\subsection{Circumscription of Hypericum}

Our phylogenetic results based on plastid and nuclear data are congruent with the division of Hypericaceae into three tribes: Cratoxyleae, Vismieae, and Hypericeae, but reject the monophyly of Hypericum (Figs. 2 and 3). Genus Triadenum is included within the New World group (clade B) in agreement with previous studies (Nürk et al., 2012; Ruhfel et al., 2011). Nürk et al. (2012) placed Thornea as Hypericum sister group whereas Ruhfel et al. (2011) considered this genus as part of Hypericum. Our ITS tree places Thornea in a polytomy with section Elodes-Adenotrias and the rest of Hypericum, so we cannot confirm its affiliation. The circumscription of Hypericum has long been controversial with different authors including within the Hypericeae genera Santomasia, Lianthus, Thornea, and Triadenum (Bentham, 1862; Choisy, 1821; Keller, 1925, 1983), and others excluding the Hypericum sections Elodes and Adenotrias (Kimura, 1951; Spach, 1836a, 1836b). One of the most discussed characters is the presence of fasciclodes between the stamen fascicles. Fasciclodes are absent in the majority of Hypericum species, but are present in other tribes and genera of Hypericeae, varying in number from five (tribe Vismieae and genus Santomasia) to three (tribe Cratoxyleae, and Hypericeae genera Lianthus, Thornea, and Triadenum). Species from sections Elodes and Adenotrias are the only ones in Hypericum that exhibit (three) fasciclodes. Our Bayesian ASR reconstruction (Fig. 4) based on plas- 
tid data agrees with Nürk et al. (2012) in inferring the presence of fasciclodes as "ancestral" (plesiomorphic) within Hypericum. Other distinctive character is the shape of the corolla, which is stellate in most Hypericum species (the "ancestral" state, Fig. 4) but pseudotubular (petals are oblique to erect, given the impression of a pseudo-tubular flower) in Triadenum and the Elodes-Adenotrias clade. The deep bowl-shaped ("cyathyform") flowers seem to be a specialization of the "Ascyreia-group" and some "Afromontane" Campylosporus (Fig. 4), which was interpreted by Robson (Robson, 1981) as a local specialization to mountain climates. The fact that bird pollination has been observed in some of these species $(\mathrm{H}$. revolutum: ASM and JJA personal observation, Janeček et al., 2007; Riegert et al., 2011; H. lanceolatum: Michenea et al., 2006) seems to confirm the hypothesis that cyathyform flowers evolved as a specialized character in Hypericum (Fig. 4).

\subsection{Phylogenetic relationships and sectional classification}

Our phylogenetic results (Figs. 2 and 3) suggest that the current sectional classification of Hypericum needs to be reconsidered, with twelve sections being para- or polyphyletic, eight monotypic and only three confirmed to be monophyletic (Table 3 ). Our results are in general comparable with those of Nürk et al. (2012) based on ITS, with the exception that we recovered the sections Campylosporus, Coridium and Triadenioides as not monophyletic (see be- low). Instead, the phylogeny is divided into several clades that are geographically segregated. Below, we describe these clades and the main morphological traits that support them (as inferred from our ASR analysis, Fig. 4).

(1) The Elodes-Adenotrias lineage (Clade A): The monotypic section Elodes and section Adenotrias (three species, represented here by $H$. aegypticum) form a clade in the chloroplast phylogeny and the BEAST chronogram (Fig. 3, Fig. 5), whose ancestor is characterized by a shrub habit, absence of dark glands, three fasciclodes, reticulate seed testa, pseudo-tubular corolla, and three partially united stamen fascicles. These lineages have sometimes been excluded from Hypericum based on their anomalous flower structures (see above), but our results agree with those of Nürk et al. (2012) in placing them as an early-branching lineage, sister-group to the remaining species.

(2) The New World group (Clade B) comprises species from the genus Triadenum sister-group of the American sections Myriandra, Brathys and Trigynobrathys. Unlike Pilepić et al. (2011), we recovered Myriandra as monophyletic, but inferred Trigynobrathys and Brathys as poly- or paraphyletic. We propose to merge these sections into a larger "Brathys-group" following Nürk et al. (2012). The ancestors of this group were probably shrubs with three fasciclodes, reticulate seed testa, stellate

Table 3

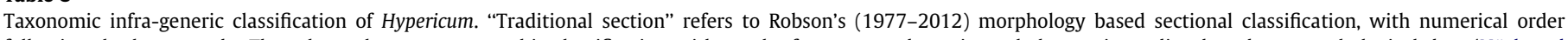

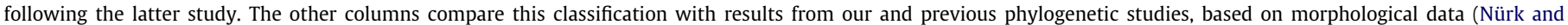

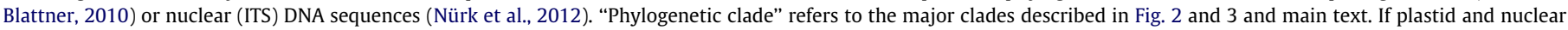

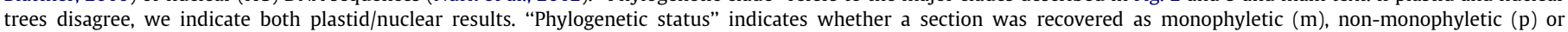

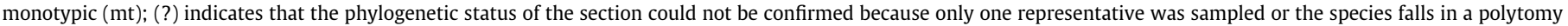
with taxa from other sections).

\begin{tabular}{|c|c|c|c|c|c|}
\hline & Traditional section & Phylogenetic clade & Phylogenetic status & Nürk and Blattner (2010) & Nürk et al. (2012) \\
\hline 1 & Campylosporus (Spach) R. Keller & $\mathrm{D}$ & $\mathrm{p}$ & $\mathrm{m}$ & $\mathrm{m}$ \\
\hline 2 & Psorophytum (Spach) Nyman & $\mathrm{D}$ & $\mathrm{mt}$ & $\mathrm{mt}$ & $\mathrm{mt}$ \\
\hline 3 & Ascyreia Choisy & $\mathrm{D}$ & $\mathrm{p}$ & $\mathrm{p}$ & $\mathrm{p}$ \\
\hline 4 & Takasagoya (Y. Kimura) N. Robson & $\mathrm{D}$ & $?$ & $\mathrm{p}$ & $?$ \\
\hline 5 & Androsaemum (Duhamel) Gordon & $\mathrm{C}$ & $\mathrm{m}$ & $\mathrm{m}$ & $\mathrm{m}$ \\
\hline 6 & Inodora Stef. & $\mathrm{E}$ & $\mathrm{mt}$ & $\mathrm{mt}$ & $\mathrm{mt}$ \\
\hline $6 a$ & Umbraculoides N. Robson & - & - & $\mathrm{mt}$ & - \\
\hline 7 & Roscyna (Spach) R. Keller & $\mathrm{D}$ & $?$ & $\mathrm{~m}$ & $\mathrm{p}$ \\
\hline 8 & Bupleuroides Stef. & $\mathrm{C}$ & $\mathrm{mt}$ & $\mathrm{mt}$ & $\mathrm{mt}$ \\
\hline 9 & Hypericum & $\mathrm{E}$ & $\mathrm{p}$ & $\mathrm{p}$ & $\mathrm{p}$ \\
\hline $9 a$ & Concinna N. Robson & - & - & $\mathrm{mt}$ & $\mathrm{mt}$ \\
\hline $9 b$ & Graveolentia N. Robson & $\mathrm{E}$ & $?$ & $\mathrm{p}$ & $\mathrm{p}$ \\
\hline $9 c$ & Sampsonia N. Robson & $\mathrm{C}$ & $?$ & $\mathrm{~m}$ & $\mathrm{~m}$ \\
\hline $9 d$ & Elodeoida N. Robson & $\mathrm{E}$ & $?$ & $\mathrm{p}$ & $\mathrm{p}$ \\
\hline $9 e$ & Monanthema N. Robson & $\mathrm{E} / \mathrm{D}$ & $\mathrm{p} / ?$ & $\mathrm{p}$ & $?$ \\
\hline 10 & Olympia (Spach) Nyman & $\mathrm{E}$ & $? / \mathrm{m}$ & $\mathrm{m}$ & $\mathrm{m}$ \\
\hline 11 & Campylopus Boiss. & $\mathrm{E}$ & $\mathrm{mt}$ & $\mathrm{mt}$ & $\mathrm{mt}$ \\
\hline 12 & Origanifolia Stef. & - & - & $\mathrm{m}$ & $\mathrm{m}$ \\
\hline 13 & Drosocarpium Spach & $\mathrm{E}$ & $\mathrm{p}$ & $\mathrm{m}$ & $\mathrm{p}$ \\
\hline 14 & Oligostema (Boiss.) Stef. & E & $\mathrm{m} / ?$ & $\mathrm{p}$ & $\mathrm{m}$ \\
\hline 15 & Thasia Boiss. & $\mathrm{E}$ & $\mathrm{mt}$ & $\mathrm{mt}$ & - \\
\hline 16 & Crossophyllum Spach & $\mathrm{E}$ & $\mathrm{p}$ & $\mathrm{m}$ & $?$ \\
\hline 17 & Hirtella Stef. & $\mathrm{E}$ & $?$ & $\mathrm{p}$ & $\mathrm{p}$ \\
\hline 18 & Taeniocarpium Jaub. \& Spach & $\mathrm{E}$ & $\mathrm{p}$ & $\mathrm{p}$ & $\mathrm{p}$ \\
\hline 19 & Coridium Spach & $\mathrm{E}$ & $\mathrm{p} / \mathrm{m}$ & $\mathrm{m}$ & $\mathrm{m}$ \\
\hline 20 & Myriandra (Spach) R. Keller & B & $\mathrm{m}$ & $\mathrm{m}$ & $\mathrm{m}$ \\
\hline 21 & Webbia (Spach) R. Keller & $\mathrm{C}$ & $\mathrm{mt}$ & $\mathrm{mt}$ & $\mathrm{mt}$ \\
\hline 22 & Arthrophyllum Jaub. \& Spach & $\mathrm{C}$ & $?$ & $\mathrm{p}$ & $\mathrm{m}$ \\
\hline 23 & Triadenioides Jaub. \& Spach & $\mathrm{C}, \mathrm{E}$ & $\mathrm{p}$ & $\mathrm{p}$ & $\mathrm{m}$ \\
\hline 24 & Heterophylla N. Robson & $\mathrm{E}$ & $\mathrm{mt}$ & $\mathrm{mt}$ & $\mathrm{mt}$ \\
\hline 25 & Adenotrias (Jaub. \& Spach) R. Keller & A & $?$ & $\mathrm{~m}$ & $?$ \\
\hline 26 & Humifusoideum R. Keller & $\mathrm{E}$ & $?$ & $\mathrm{p}$ & $?$ \\
\hline 27 & Adenosepalum Spach & $\mathrm{E}$ & $\mathrm{p}$ & $\mathrm{p}$ & $\mathrm{p}$ \\
\hline 28 & Elodes (Adans.) W. Koch ${ }^{\mathrm{a}}$ & A & $\mathrm{mt}$ & $\mathrm{mt}$ & $\mathrm{mt}$ \\
\hline 29 & Brathys (Mutis ex L. f.) Choisy & $\mathrm{B}$ & $\mathrm{p}$ & $\mathrm{p}$ & $\mathrm{p}$ \\
\hline 30 & Trigynobrathys (Y. Kimura) N. Robson & B & $\mathrm{p}$ & $\mathrm{p}$ & $\mathrm{p}$ \\
\hline
\end{tabular}

a This section is called Tripentas in Robson (2012) 
corollas and three partially united stamen fascicles, with five united stamen fascicles as an autapomorphy of section Myriandra and the "Brathys-group" (Fig. 4).

The Old World group is the most diversified in terms of number of species and morphological sections and, based in our phylogenetic results, we estimate it contains approximately 270 of the 496 (60\%) described species. It is subdivided into three major clades:

(1) Clade C ("Androsaemum-group") comprises species from sections Bupleuroides, Webbia, Androsaemum, Sampsonia (only in ITS), Triadenioides and Arthrophyllum, the last two falling in a polytomy, and receives moderate or low support in the cPDNA and ITS trees (it is also recovered in the BEAST dated tree). We found that Triadenioides is polyphyletic, contrary to Nürk et al. (2012) findings that had a reduced sampling of this section. The ancestor of the group is characterized by a shrub habit, absence of dark glands and fasciclodes, reticulate seed testa, stellate flowers, and three partially united stamen fascicles. Free stamen fascicles seem to be apomorphic of section Androsaemum.

(2) Clade D is divided into two clades: the "Afromontane-group" of section Campylosporus and the "Ascyreia-group", which includes mainly species from the large Asian section Ascyreia, but also from Roscyna, Takasagoya, and the monotypic Psorophytum (Fig. 3). Some African species of Campylosporus, $H$. synstylum, $H$. balfourii and $H$. socotranum, fall within the "Ascyreia-group", rendering this section polyphyletic contrary to Nürk et al. (2012); this could be explained because we included a larger sampling of this African section in our study. These species differ from the "Afromontane-group" in having deciduous petals and stamens and in the absence of dark glands, all characteristics of the "Ascyreia-group" (Fig. 4). The ancestors of clade D was a darkglandless shrub with reticulate testa, stellate flowers, and five free stamen fascicles, the latter seem to be autapomorphic of this group. The "Afromontane-group" shows also several derived characters, such as the tree habit form, presence of dark glands, and cyathiform corollas.

(3) Clade E is the most numerous and variable concerning distribution and morphology. The ancestor of this clade was characterized by the presence of dark glands and herbaceous habit, absence of fasciclodes, stellate flowers, three partially united stamens, and reticulate seed testa, although there is considerable variation in the last two characters in the current species (Fig. 4). Although resolution within this clade was low, two subclades or groups can be recognized. The "Hirtella-group" comprises species from sections Coridium, Monanthema, Inodora and Triadenioides, as well as Taeniocarpium and Hirtella. This group, which was also recovered by Nürk et al. (2012) and Crockett et al. (2004), receives moderate support in the ITS tree, the concatenated "No-missing" plastid dataset and some of the individual chloroplast trees (SI Fig. 2, it is also recovered by the BEAST tree, Fig. 5), but not in the combined "All-specimens" cpDNA tree (Fig. 3). The rest of species and sections are grouped into the "Hypericum-group", with generally poor internal resolution (Figs. 2 and 3).

\subsection{Spatio-temporal evolution in Hypericum}

In line with the tennets of Phylogenetic Biogeography (Brundin, 1966; Hennig, 1966), Robson (1981) hypothesized that there was a parallelism between the morphological and geographic evolution of Hypericum. He described evolutionary trends for the main diagnostic characters ("morphoclines"), and noted that these morphoclines were generally correlated with distributional trends, defining "geomorphoclines" (Robson, 2006). In particular, Robson hypothesized that the genus originated in Africa before the break up of Gondwana, and that the characters exhibited by the Afromontane species $(H$. bequarteri and $H$. revolutum), such as treelet habit and presence of dark glands, were ancestral in the genus. Geographic spread of Hypericum from Africa to other continents would have been accompanied by the appearance of derived traits such as the herbaceous habit and the loss of dark glands.

Our BEAST-BIB reconstruction shows a different scenario (Fig. 5). The ancestors of family Hypericaceae are actually reconstructed as African. Coding for the alternative areas for widespread species did not change ASR within Hypericum, but it did favor WP as ancestral area for the root and the ancestor of Hypericeae-Vismieae, although Africa was inferred with similar probability (results not shown). With the exception of Cratoxylum in SE Asia and Vismia widespread in South America and Africa, all other genera in tribes Vismieae and Cratoxyleae are African, so our sampling of outgroups is probably representative of the distribution of the group. Moreover, a more inclusive analysis on the clusioid clade, including representatives of virtually every genera (Ruhfel, 2011), reconstructed Africa as the ancestral area of Hypericaceae and that of the MRCA of Vismieae and Hypericeae. Therefore, it is likely that Africa is the area of origin for Hypericaceae.

The ancestors of Hypericum are inferred to have dispersed from Africa to the western part of Europe in the Early Tertiary (Fig. 5), probably using the dispersal route provided by the collision of the African and Iberian Plates in the Paleocene (Meulenkamp and Sissingh, 2003; Rosenbaum et al., 2002). Colonization of the Northern Hemisphere by Hypericum stem-lineages seem to have been concurrent with the climate warming that peaked in the Early Eocene Climatic Optima (EECO in Fig. 5; Zachos et al., 2001). At that time, tropical climates characterized higher latitudes, and a uniform vegetation belt, a mixture of deciduous and evergreen plants, the "boreotropical forest", covered the Northern landmasses from Asia to Europe and North America (Tiffney, 1985a, 1985b; Wolfe, 1975). Hypericum ancestors were probably tropical shrubs, much like related tribes Vismieae and Cratoxyleae, and could have used these favorable tropical conditions to invade the Holarctic.

Crown-group Hypericum is reconstructed as having evolved in the West Palearctic region (Fig. 5), with an initial diversification $35 \mathrm{Ma}$ (CI 34-37 Ma, Fig. 5). This range is within the dates inferred by Ruhfel (2011), who estimated the first diversification in Hypericum (crown-age) between 30.8 and $37.3 \mathrm{Ma}$, depending on the position of Paleoclusia (see above). The origin of the crown group Hypericum seems to coincide with a dramatic drop in global temperatures and increase in seasonality; the Terminal Eocene Event (TEE in Fig. 5; Zachos et al., 2001). This event promoted the selection of cool-adapted boreotropical elements and the expansion of deciduous vegetation at northern latitudes, the "mixed-mesophytic forest" (Tiffney, 1985a, 1985b). Some specializations in Hypericum such as the change on habit form and the evolution of unspecialized corollas may be related to the adaptation of these ancestral lineages to the new temperate conditions. On the other hand, Davis et al. (2005) reconstructed the ancestors of Hypericaceae as inhabitants of open woodland habitats in tropical latitudes, which could indicate pre-adaptation to more open environments. However, this result needs to be carefully interpreted since the sampling within the family was very reduced (only Vismia and Hypericum were included).

Hypericum might have been part of the Mid-Tertiary mixedmesophytic forest, as evidenced by the appearance of Hypericum Early-Mid Miocene seeds on relict assemblages of this forest in West Yunnan (China; Zhao et al., 2004). Our hypothesized scenario of a West Palearctic diversification contrasts with the presence of the oldest fossil remains of Hypericum in the Late Eocene of West Siberia (Meseguer and Sanmartín, 2012). This suggests that Hypericum ancestors were also distributed in the Eastern Palearctic (area "EP" 
in Fig. 5). Bayesian inference of ancestral states does not allow polymorphic (widespread) ancestors, which might be unrealistic for an old group like Hypericum that evolved during a time of major geologic changes. However, the Eastern Palearctic is actually poorly represented in Hypericum: most lineages within this region, like the "Ascyreia-group", are restricted to the southern portion (China, Himalaya), whereas the northern part of EP (where $H$. antiquum was found) is now represented by a few widespread species (Robson, 1981). Moreover, our analysis included a good sampling of these EP lineages (e.g., Roscyna, Takasagoya, Monanthema, and Hypericum), so our results cannot be attributed to a biased representation of this region. Instead, it is more likely that large-scale extinction in the northern part of the Eastern Palearctic, associated to the Terminal Eocene Event (TEE) and the Late Tertiary climatic fluctuations (Sanmartin et al., 2001), would explain the disagreement between our reconstruction and the fossil record.

The ancestor of the New and Old World lineages is reconstructed to have dispersed from the Palearctic to North America at the end of the Eocene (Fig. 5). At this time, two land corridors connected all northern landmasses: the North Atlantic Land Bridge (NLAB) and the Beringian Land Bridge, BLB (McKenna, 1983; Tiffney, 1985a, 1985b; Wolfe, 1975). Although the general view is that the NALB only persisted until the Early Eocene (McKenna, 1983; Sanmartin et al., 2001; Tiffney, 1985a, 1985b), some authors suggest a longer connection (Donoghue and Moore, 2003; Gronlie, 1979; Wen, 1999). The southern fringes of the Beringian Bridge were probably suitable for cool-tolerant taxa during the Eocene, and this connection is thought to have lasted until the Late Miocene for temperate taxa (Sanmartin et al., 2001). In any event, it is likely that Hypericum ancestors used the geographical proximity of North America and Eurasia and the existence of a uniform forest belt, the Eocene boreotropical forest or its successor, the Oligocene mixed-mesophytic forest, to migrate across the northern landmasses. Davis et al. (2002, 2004) also suggested a northern latitude migration to explain the biogeographic history of the pantropical family Malpighiaceae, and similar hypotheses have been proposed for other plant groups (Donoghue and Smith, 2004; Tiffney, 1985a, 1985b; Wen, 1999; Wen and Ickert-Bond, 2009; Wolfe, 1975; Xiang et al., 1998). The trans-Beringian connection seems to have persisted for Hypericum until the Late Miocene, as can be observed in the split between $H$. erectum (Eastern Palearctic) and the Nearctic H. formosum-H. scouleri (Fig. 5). Another example is Triadenum, which has species in eastern North America and northeast Asia, the latter not included in our study. Diversification within the New World group started in the Early Oligocene in North America, with some taxa migrating to Africa probably by long distance dispersal ( $H$. lalandii). Dispersal to South America was concurrent with the rising of mountain chains in Central and northern South America in the Late Miocene ca. $12 \mathrm{Ma}$ (Hoorn et al., 2010). Precisely the last peak of mountain building in the Northern Andes at c. $4.5 \mathrm{Ma}$ (Hoorn et al., 2010) coincides with the start of diversification (crown-node) of the South American radiation in the "Brathys-group" (Fig. 5).

The Old World clade began also diversifying in the Oligocene within the Western Palearctic region (Fig. 5). From there, several dispersal events to the rest of the world are inferred, which are mainly dated after the Mid Miocene Climatic Optimum (MMCO, Fig. 5). Dispersal events back to Africa occurred at different times, but mostly around the Late Oligocene-Early Miocene and the Late Miocene-Pliocene (Fig. 5). The Oligocene-Early Miocene was a warm and humid period, with wide extensions of rainforests from northern Africa to South Africa (Jacobs, 2004; Plana, 2004). This rainforest was fragmented and replaced by a woodland savannah following the aridification process that started in Africa in the Mid Miocene (Coetzee, 1993). This was the result of a combination of factors, the Eastern uplift of the continent, the closure of the Tethys Sea, and the deterioration of global climatic conditions at the end of the Miocene (Zachos et al., 2001). The geographic disjunction between Africa and WP observed in the MRCA of clade C (the lineage of $H$. scopulorum-H.tortuosmum in Socotra and the Mediterranean-Macaronesian clade $H$. pamphylicum-H. grandiflorum, Fig. 5) could be evidence of a formerly widespread African flora fragmented by these climatic events (Sanmartín et al., 2010). Later dispersals to Africa in the Late Miocene-Pliocene in clade E are concurrent with the Messinian Salinity crisis (c. 7.2 Ma, Krijgsman et al., 1999) and with a period of high tectonic activity (c. 7-8 Ma) that led to the uplift of the Eastern Arc Mountains and the uplands of West Central Africa with the Cameroon volcanic line (Plana, 2004). Indeed, the diversification of the "Afromontane-group" in section Campylosporus (clade D) is contemporary with the maximum uplift of the Eastern African Rift system in the Pliocene that ended with the formation of the Ethiopian highlands (5-2 Ma, Sepulchre et al., 2006).

Dispersal from Africa to Asia by the ancestors of the "Ascyreiagroup" (clade D) in the Late Miocene (Fig. 5) might have been facilitated by the collision of the Arabian plate with Eurasia (c. $16 \mathrm{Ma}$ ) and the uplift of the Red Sea margins (13.8 Ma; (Goudie, 2005)). Another possibility is that the "Ascyreia-group" in East Asia (China) is a relict assemblage of the Mid-Tertiary mixed-mesophytic forest, as suggested by the findings of Early-Mid Miocene seeds in this region (Zhao et al., 2004). This further suggests the possibility of a dispersal event in the opposite direction, from Asia to Africa, and of extinction misleading again our reconstruction. The mixed-mesophytic forest went extinct in Europe and western North America following the drastic climate cooling at the end of the Tertiary, but survived in East Asia and eastern North America (Tiffney, 1985a, 1985b).

Hypericum colonization and diversification in the Irano-Turanian-Himalayan region (ITH) is dated during the Late Miocene (Fig 5). The paleogeographic history of this region is complex: it was formed by the collision of the Indian and Arabian plates against Eurasia, and the subsequent rise of several mountains ranges. Periods of major uplift in this region seem to coincide with several dispersal events of Hypericum lineages to this region: the "Hirtellla-group" entered the Iranian Plateau (Fig. 5) after the collision of the Arabian and Eurasian plates that resulted in the Late Miocnee uplift of the Zagros Mountains (10 Ma, Sanmartin, 2003). Similarly, some members of the "Ascyreia-group" colonized the Himalayan Mountains (Fig. 5) coincident with a major orogenic uplift of the Himalayan range, c 7-8 Ma (Wang et al., 2009). From our results, it seems possible that the rising of the Neogene mountain ranges (e.g., Northern Andes, Eastern African Mountains, Himalayan mountains) played an important role in the colonization of tropical and subtropical regions in Hypericum, where mountain uplift favoured the appearance of new niches for temperate adapted taxa.

\section{Acknowledgments}

This work was funded by the Spanish Ministry of Education and Science (project CGL2009-13322-C03-01/BOS) to I.S. and a PhD research grant AP-2007-01698 to A.S.M. The authors are very thankful to the following herbaria for providing plant material: MA, MO, A, BOZ, AAH, GB, W, AAU, BCN, BC, UPS, S, and to M. Velayos and C. Baranda for helping with loan of specimens. We also thank N. Nürk for providing DNA samples and for sharing unpublished results; J. Molero, A. Hilpold, A. Gonzalez, C. Tauleigne, M. Serrano, P. Vargas, J. Ruiz, B. Oxelman, for collection of fresh material; I. Marques, E. Cano, F. Duran, G. Andreu, and G. Sanjuanbenito for technical support; J. Fuertes, T. Marcussen, S. Buerki, C.L. Anderson and A. Hilpold for help at different stages of this research. J. Fuertes and R. Riina for valuable comments on the manuscript. 


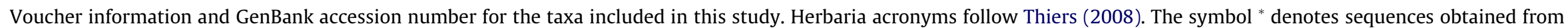
GenBank. The symbol denotes psbA-trnH sequences whose phylogenetic position was incongruent with those of other nuclear and plastid markers (see Section 3.2).

\begin{tabular}{|c|c|c|c|c|c|c|c|c|}
\hline \multirow[t]{2}{*}{ Specie } & \multirow[t]{2}{*}{ Section } & \multirow[t]{2}{*}{ ID } & \multirow[t]{2}{*}{ Voucher } & \multirow[t]{2}{*}{ Locality } & \multicolumn{4}{|c|}{ Genbank accession numbers } \\
\hline & & & & & ITS & $\operatorname{trnL}-\operatorname{trn} F$ & psbA-trnH & trnS-trnG \\
\hline \multicolumn{9}{|l|}{ Hypericeae } \\
\hline $\begin{array}{l}\text { Hypericum aethiopicum subsp. aethiopicum } \\
\text { Thunb }\end{array}$ & Adenosepalum & C116 & GB1810 (GB) & $\begin{array}{l}\text { South Africa, E. Cape } \\
\text { Province }\end{array}$ & КC709369 & KC709070 & - & KC708934 \\
\hline $\begin{array}{l}\text { Hypericum aethiopicum subsp. sonderi } \\
\text { (Bredell) N. Robson }\end{array}$ & Adenosepalum & C110 & Aedo 14946 (MA) & $\begin{array}{l}\text { South Africa, Orange } \\
\text { Free State }\end{array}$ & КC709367 & KC709067 & KC709223 & - \\
\hline $\begin{array}{l}\text { Hypericum aethiopicum subsp. sonderi } \\
\text { (Bredell) N. Robson }\end{array}$ & Adenosepalum & C131 & GB2057 (GB) & $\begin{array}{l}\text { South Africa, } \\
\text { Johanesburg }\end{array}$ & KC709375 & KC709075 & - & - \\
\hline Hypericum afrum Lam. & Adenosepalum & C62 & Dubuis s.n. (MA) & Algeria, Wilaya El Tarf & - & KC709030 & - & - \\
\hline Hypericum annulatum Moris & Adenosepalum & $\mathrm{C} 7$ & Ryding 1485 (UPS) & Ethiopia, Eritrea & KC709308 & KC708998 & KC709168 & KC708889 \\
\hline Hypericum athoum Boiss. \& Orp & Adenosepalum & AY555846 & Crockett et al., 2004 & - & AY555846* & - & - & - \\
\hline Hypericum athoum Boiss. \& Orp & Adenosepalum & $\mathrm{C} 251$ & Sanchez 171 (MA) & Bot garden Goteborg & - & KC709136 & КC709280 & - \\
\hline Hypericum caprifolium Boiss. & Adenosepalum & $\mathrm{C} 17$ & Sanchez 3.1 (MA) & Spain, Tarragona & KC709313 & KC709004 & KC709172 & KC708891 \\
\hline Hypericum caprifolium Boiss. & Adenosepalum & C18 & Sanchez 3.2 (MA) & Spain, Tarragona & КC709314 & KC709005 & КC709173 & KC708892 \\
\hline Hypericum coadunatum C. Smith ex Link & Adenosepalum & C144 & Aldasoro A10353 (MA) & Spain, Gran Canaria & KC709383 & KC709082 & KC709233 & KC708942 \\
\hline Hypericum conjungens N. Robson & Adenosepalum & C194 & Mwasumbi 16191A (BM MO) & Tanzania, Mbeya & KC709412 & KC709113 & - & - \\
\hline Hypericum conjungens N. Robson & Adenosepalum & C314 & Mbago BG-Af $331(\mathrm{Z})$ & Tanzania, Iringa & - & - & - & KC708992 \\
\hline Hypericum delphicum Boiss. \& Heldr. & Adenosepalum & AY555845 & Crockett et al., 2004 & - & AY555845* & - & - & - \\
\hline Hypericum delphicum Boiss. \& Heldr. & Adenosepalum & FJ694197 & Hazler-Pilepic \& Blazina 2011 & - & FJ694197* & - & - & - \\
\hline Hypericum foliosum Aiton & Adenosepalum & C114 & Aedo 10536 (MA) & $\begin{array}{l}\text { Portugal, Azores, Isla } \\
\text { Terceira }\end{array}$ & - & KC709069 & KC709224 & - \\
\hline Hypericum glandulosum Aiton & Adenosepalum & C145 & Aldasoro A10325 (MA) & Spain, Tenerife & КC709384 & KC709083 & KC709234 & КС708943 \\
\hline Hypericum glandulosum Aiton & Adenosepalum & C150 & Aldasoro A10349 (MA) & Spain, Tenerife & KC709388 & KC709087 & - & KC708947 \\
\hline Hypericum kiboënse Oliver & Adenosepalum & $\mathrm{C} 1$ & Jonsell 2135 (UPS) & Tanzania, Kilimanjaro & - & KC708993 & - & KC708885 \\
\hline Hypericum kiboënse Oliver & Adenosepalum & C240 & Sanchez 94 (MA) & $\begin{array}{l}\text { Kenya, Kinangop, } \\
\text { Aberdares Mts. }\end{array}$ & KC747115 & KC709132 & KC709278 & KC708979 \\
\hline Hypericum kiboënse Oliver & Adenosepalum & $\mathrm{C} 6$ & Hedberg 6350 (UPS) & Tanzania, Kitoto & KC709307 & KC708997 & - & KC708888 \\
\hline Hypericum lanuginosum Lam. & Adenosepalum & C127 & Wok s.n. (GB) & Israel, Galilee & KC709372 & - & - & - \\
\hline Hypericum lanuginosum Lam. & Adenosepalum & C162 & Haller s.n. (BC) & Israel, Nahal Qetalau & - & KC709092 & - & - \\
\hline Hypericum montanum L. & Adenosepalum & FJ694211 & Hazler-Pilepic \& Blazina 2011 & - & FJ694211* & - & - & - \\
\hline Hypericum montanum L. & Adenosepalum & C208 & Aldasoro 14180 (MA) & Spain, Santander & KC709424 & KC709124 & KC709270 & KC708971 \\
\hline Hypericum montanum L. & Adenosepalum & $\mathrm{C} 90$ & Ferrero s.n. (MA) & Spain, Cuenca & - & KC709052 & - & KC708924 \\
\hline Hypericum naudinianum Coss. \& Durieu & Adenosepalum & C157 & Mateos 7107/95 (BC) & Morroco, Chefchaouen & - & KC709090 & KC709239 & - \\
\hline Hypericum psilophytum (Diels) Maire & Adenosepalum & C 38 & Aldasoro A9867 (MA) & $\begin{array}{l}\text { Algeria, Hoggar } \\
\text { Mountains }\end{array}$ & KC709327 & KC709018 & KC709186 & KC708905 \\
\hline Hypericum pubescens Boiss. & Adenosepalum & C104 & Calvo JC1352 (MA) & Spain, Cadiz & KC709361 & KC709061 & KC709218 & KC708929 \\
\hline Hypericum reflexum L. f. & Adenosepalum & C143 & Aldasoro A10352 (MA) & Spain, Gran Canaria & KC709382 & KC709081 & - & KC708941 \\
\hline Hypericum reflexum var. reflexum L. f. & Adenosepalum & $\mathrm{C} 112$ & Marrero s.n. (MA) & Spain, Gran Canaria & KC709368 & KC709068 & - & - \\
\hline $\begin{array}{l}\text { Hypericum sinaicum Steudel \& Hochst. ex } \\
\text { Boiss. }\end{array}$ & Adenosepalum & C197 & Danin 962609 (BM) & Jordan, Edom & KC709414 & KC709116 & KC709262 & - \\
\hline Hypericum somaliense N. Robson & Adenosepalum & $\mathrm{C} 4$ & Thulin 9075 (UPS) & Somalia, Mirci & KC709305 & KC708995 & KC709166 & - \\
\hline
\end{tabular}


Hypericum tomentosum L.

Hypericum tomentosum $\mathrm{L}$.

Hypericum aegypticum L.

Hypericum aegypticum subsp. webbii

(Spach) N. Robson

Hypericum androsaemum $\mathrm{L}$.

Hypericum androsaemum L.

Hypericum grandifolium Choisy

Hypericum grandifolium Choisy

Hypericum hircinum L.

Hypericum hircinum subsp. metroi $\mathrm{L}$.

Hypericum x_inodorum Miller

Hypericum pamphylicum N. Robson \& P. Davis

Hypericum acmosepalum N. Robson

Hypericum acmosepalum N. Robson

Hypericum beanii N. Robson

Hypericum beanii N. Robson

Hypericum calycinum L.

Hypericum calycinum $\mathrm{L}$.

Hypericum choisianum Wall. ex N. Robson Ascyreia

Hypericum choisianum Wall. ex N. Robson Ascyreia

Hypericum curvisepalum N. Robson Ascyreia

Hypericum dyeri Rehder

Hypericum elatoides Keller

Hypericum forrestii (Chitt) Robson

Hypericum forrestii (Chitt) Robson

Hypericum forrestii (Chitt) Robson

Hypericum henryi H. Levl. \& Van.

Adenosepalum C19

Adenosepalum C20

Adenotrias C161

Adenotrias

C136

Androsaemum FJ694190 Hazler-Pilepic \& Blazina 2011

Androsaemum C60

Androsaemum C146

Androsaemum C147

Androsaemum FJ69420

Androsaemum C108

Androsaemum FJ694208

Arthrophyllum C196

Ascyreia

Ascyreia

Ascyreia

Ascyreia

Ascyreia

Ascyreia
Ascyreia

Ascyreia

Ascyreia

Ascyreia

Ascyreia

Ascyreia

Hypericum henryi subsp_uraloides (Rehder) Ascyreia

N. Robson

Hypericum hookerianum Wight \& Arn.

Hypericum hookerianum Wight \& Arn.

Hypericum kouytchense $H$. Lév.

Hypericum kouytchense H. Lév.

Hypericum kouytchense H. Lév.

Hypericum lancasteri N. Robson

Hypericum lancasteri N. Robson

Ascyreia

Ascyreia

Ascyreia

Ascyreia

Ascyreia

Ascyreia

Ascyreia

Ascyreia

Ascyreia

Hypericum leschenaultii Choisy

Hypericum longistylum subsp. longistylum Ascyreia Oliver

Hazler-Pilepic \& Blazina 2011

Hazler-Pilepic \& Blazina 2011

AY555851 Crockett et al., 2004 k052 (AAH)

AY555852 Crockett et al., 2004 K047 (AAH)

AY555861 Crockett et al., 2004

C58 Sanchez 10 (MA)

AY555856 Crockett et al., 2004

C300 $421(\mathrm{AAH})$

C303 Bartholomew $120(\mathrm{AAH})$

C270 Steward $24528(\mathrm{~W})$

C305 Boufford 26156 (AAH)

AY555858 Crockett et al., 2004

FJ694202 Hazler-Pilepic \& Blazina 2011 -

C296 Sino-British exp. Cangshan 423 (AAH)

C307 Li Heng 11347 (A)

AY555859 Crockett et al., 2004

C284 Larsen 44980 (AAU)

AY555853 Crockett et al., 2004

FJ694210 Hazler-Pilepic \& Blazina 2011

FJ788906 Kosuth et al., 2010

AY555854 Crockett et al., 2004 K047 (AAH)

C311 Sino-British exp. Cangshan 1096 (A)

AY555857 Crockett et al., 2004

C301 Lancaster 1833 (AAH)
Sanchez 4.1 (MA)

Sanchez 4.2 (MA)

Italy, Sicilia

Greece, Santorini
KC709315 KC709006 KC709174 KC708893

KC709316 KC709007 KC709175 KC708894

KC709391 KC709091 KC709240 KC708949

KC709380 KC709079 KC709231 KC708939

FJ694190* -

Royal Bot garden Madrid KC709337 KC709028 KC709196 KC708913

$\begin{array}{ll}\text { Aldasoro A10354 (MA) } & \text { Spain, Gran Can } \\ \text { Aldasoro A10316 (MA) } & \text { Spain, Tenerife }\end{array}$

Calvo JC2576 (MA) Morroco, Taza-Al (1)

C302 Sino-British exp. Cangshan China, W Yunnan

C298 Sino-British exp. Cangshan China, W Yunnan

C309 Bartholomew 631 (A)

C299 Sino-British exp. Cangshan China, W Yunnan

China, Hubei pain, Gran Canaria

KC709385 KC709084 KC709235 KC708944

KC709386 KC709085 KC709236 KC708945 FJ694204* -

KC709365 KC709065 KC709221 KC708933

FJ694208* KC709115 KC709261 -

AY555851*

KC709446 KC709154 KC709294 -

AY555852* -

AY555861* -

Royal Bot garden Madrid KC709335 KC709026 KC709194 KC708911

AY555856* -

China, W Yunnan

China, W Yunnan

Pakistan, Swat

China, Henan

China, W Yunnan

China, Yunnan

Thailand, ChiangMa

China, W Yunnan

China, W Yunnan

KC709152 KC709292

KC709155 KC709295

KC709440 -

AY555858* -

FJ694202* -

KC709448 KC709159 KC709298 KC708990 AY555859* -

KC709148 KC709290 KC708987

KC709450 KC709160 -

AY555853* -

FJ694210* -

AY555854* -

FJ788906* -

KC709444 KC709151 KC709291

$\begin{array}{llll}- & \text { KC709161 } & \text { KC709299 } & \text { KC708991 }\end{array}$

AY555857* -

KC709445 KC709153 KC709293 -
- KC709150 -

KC709157 KC709296 KC708988 


\begin{tabular}{|c|c|c|c|c|c|c|c|c|}
\hline \multirow[t]{2}{*}{ Specie } & \multirow[t]{2}{*}{ Section } & \multirow[t]{2}{*}{ ID } & \multirow[t]{2}{*}{ Voucher } & \multirow[t]{2}{*}{ Locality } & \multicolumn{4}{|c|}{ Genbank accession numbers } \\
\hline & & & & & ITS & $\operatorname{trnL}-\operatorname{trnF}$ & psbA-trnH & trnS-trnG \\
\hline Hypericum monogynum L. & Ascyreia & C304 & Lancaster $1828(\mathrm{AAH})$ & China, E. Sichuan & - & КC709156 & - & - \\
\hline Hypericum oblongifolium Choisy & Ascyreia & FJ694226 & Hazler-Pilepic \& Blazina 2011 & - & FJ694226* & - & - & - \\
\hline Hypericum oblongifolium Choisy & Ascyreia & C260 & Ewald 6258 (GB) & Pakistan, Hazara & KC709435 & - & - & - \\
\hline Hypericum patulum Thunb. Ex Murray & Ascyreia & AY555860 & Crockett et al., 2004 & - & AY555860* & - & - & - \\
\hline Hypericum patulum Thunb. Ex Murray & Ascyreia & C203 & Aldasoro 14207 (MA) & Spain, Santander & KC709419 & KC709120 & КC709266 & KC708968 \\
\hline Hypericum pseudohenryi N. Robson & Ascyreia & AY555850 & Crockett et al., 2004 & - & AY555850* & - & - & - \\
\hline Hypericum pseudohenryi N. Robson & Ascyreia & C306 & Boufford 32838 (AAH) & China, Sichuan & KC709447 & KC709158 & КC709297 & KC708989 \\
\hline Hypericum subsessile N. Robson & Ascyreia & C308 & Bartholomew 865 (A) & China, W Yunnan & КС709449 & - & - & - \\
\hline Hypericum wilsonii N. Robson & Ascyreia & FJ694225 & Hazler-Pilepic \& Blazina 2011 & - & FJ694225* & - & - & - \\
\hline Hypericum x_moserianum Luquet ex André & Ascyreia & AY555855 & Crockett et al., 2004 & - & AY555855* & - & - & - \\
\hline Hypericum aciculare Kunth & Brathys & C262 & Harling 13351 (GB) & Ecuador, Loja & KC709436 & - & - & - \\
\hline Hypericum bryoides Gleason & Brathys & C68 & Wood 4504 (MA) & Colombia, N Santander & КС709339 & KC709034 & - & - \\
\hline $\begin{array}{l}\text { Hypericum drummondii (Grev. \& Hook) } \\
\text { Torrey \& Gray }\end{array}$ & Brathys & C119 & Vicent 3958 (GB) & USA, Ohio & KC709370 & KC709071 & KC709225 & - \\
\hline Hypericum gentianoides (L) Britton & Brathys & C186 & Miller 8429 (MO) & USA, Florida & KC709408 & KC709110 & КC709258 & - \\
\hline Hypericum juniperinum Kunth & Brathys & $\mathrm{C} 83$ & Wood 4796 (MA) & Colombia, Cauca & KC709348 & KC709047 & - & - \\
\hline Hypericum laricifolium Juss. & Brathys & C266 & Persson $1622(\mathrm{~GB})$ & Ecuador, Pichinga & - & KC709141 & KC709285 & - \\
\hline Hypericum laricifolium Juss. & Brathys & C316 & Hilpold 10943 (BOZ) & Peru, Yungay & KC709451 & KC709162 & - & - \\
\hline Hypericum laricifolium Jussieu & Brathys & C263 & Zak $3484(\mathrm{~GB})$ & Ecuador, Napo & KC709437 & - & - & - \\
\hline Hypericum mexicanum L. & Brathys & $\mathrm{C} 86$ & Wood 5141 (MA) & Colombia, Boyaca & KC709351 & KC709050 & КС709209 & - \\
\hline $\begin{array}{l}\text { Hypericum pimelioides Planch. \& Linden ex } \\
\text { Triana \&Planch. }\end{array}$ & Brathys & C102 & Rangel 4025 (MA) & Colombia, Boyaca & - & KC709060 & - & - \\
\hline Hypericum quitense R. Keller & Brathys & $\mathrm{C} 257$ & Antonelly 578 (GB) & Ecuador, Azuay & KC709433 & KC709138 & KC709284 & - \\
\hline Hypericum sprucei N. Robson & Brathys & $\mathrm{C} 265$ & Molau 3263 (GB) & Ecuador, Pichincha & KC709439 & KC709140 & - & - \\
\hline Hypericum strictum Kunth & Brathys & C92 & Brak s.n. (MA) & Costa Rica, Cartago & KC709354 & KC709054 & KC709212 & - \\
\hline Hypericum bupleuroides Griseb. & Bupleuroides & FJ788898 & Kosuth et al., 2010 & - & - & - & FJ788898* & - \\
\hline Hypericum bupleuroides Griseb. & Bupleuroides & C65 & Makaschrili s.n. (MA) & Georgia, Ajara & - & KC709032 & - & - \\
\hline Hypericum cerastoides (Spach) N. Robson & Campylopus & AY555884 & Crockett et al., 2004 & - & AY555884* & - & - & - \\
\hline Hypericum cerastoides (Spach) N. Robson & Campylopus & $\mathrm{C} 72$ & s.n. (MA) & Bulgaria, Kosovo & KC709341 & KC709038 & KC709200 & KC708917 \\
\hline Hypericum balfourii N. Robson & Campylosporus & C171 & Aldasoro 14697 (MA) & Yemen, Socotra & KC709397 & KC709099 & KC709247 & KC708955 \\
\hline Hypericum bequaertii De Wild. & Campylosporus & C219 & Sanchez 36 (MA) & Uganda, Rwenzori Mts. & KC709426 & KC709127 & KC709273 & KC708974 \\
\hline Hypericum bequaertii De Wild. & Campylosporus & $\mathrm{C} 220$ & Sanchez 38 (MA) & Uganda, Rwenzori Mts. & KC709427 & KC709128 & KC709274 & KC708975 \\
\hline Hypericum dogonbadanicum Assadi & Campylosporus & C195 & Assadi 38585 (BM) & Iran, Dogonbadan & КC709413 & KC709114 & КC709260 & - \\
\hline Hypericum quartinianum A. Rich & Campylosporus & $\mathrm{C} 224$ & Sanchez 47 (MA) & $\begin{array}{l}\text { Uganda, Kisumu, Mt. } \\
\text { Elgon }\end{array}$ & KC709428 & KC709129 & KC709275 & KC708976 \\
\hline Hypericum quartinianum A. Rich & Campylosporus & C32 & Aldasoro A9986 (MA) & Ethiopia & KC709325 & KC709016 & KC709184 & КC708903 \\
\hline $\begin{array}{l}\text { Hypericum revolutum subsp. keniense } \\
\text { (Scweinf.) N.Robson }\end{array}$ & Campylosporus & C215 & Sanchez 32 (MA) & Uganda, Rwenzori Mts. & - & KC709126 & KC709272 & KC708973 \\
\hline $\begin{array}{l}\text { Hypericum revolutum subsp. revolutum Vah } \\
\text { (Schweinf) }\end{array}$ & Campylosporus & C213 & Sanchez 28 (MA) & Uganda, Rwenzori Mts. & KC709425 & KC709125 & KC709271 & KC708972 \\
\hline Hypericum revolutum Vahl (Schweinf) & Campylosporus & C82 & Castroviejo 9145SC (MA) & Equatorial Guinea, Bioko & - & KC709046 & - & - \\
\hline $\begin{array}{l}\text { Hypericum roeperanum W. G. Schimper ex A. } \\
\text { Rich }\end{array}$ & Campylosporus & C230 & Sanchez 62 (MA) & $\begin{array}{l}\text { Uganda, Kisumu, Mt. } \\
\text { Elgon }\end{array}$ & KC709429 & KC709130 & КC709276 & КС708977 \\
\hline $\begin{array}{l}\text { Hypericum roeperanum W. G. Schimper ex A. } \\
\text { Rich }\end{array}$ & Campylosporus & $\mathrm{C} 233$ & Sanchez 70 (MA) & $\begin{array}{l}\text { Uganda, Kisumu, Mt. } \\
\text { Elgon }\end{array}$ & - & KC709131 & KC709277 & KC708978 \\
\hline
\end{tabular}


Hypericum roeperanum W. G. Schimper ex A. Campylosporus AY555863 Crockett et al., 2004 Rich

Hypericum socotranum subsp. socotranum Campylosporus C167 Good

Hypericum synstylum N. Robson

Hypericum synstylum N. Robson

Hypericum amblycalyx Coust. \& Gandoger

Hypericum coris L.

Hypericum coris $\mathrm{L}$.

Hypericum empetrifolium var. oliganthum Willd.

Hypericum empetrifolium Willd.

Hypericum empetrifolium Willd.

Hypericum empetrifolium Willd.

Hypericum ericoides $\mathrm{L}$.

Hypericum ericoides $\mathrm{L}$.

Hypericum aucheri Jaub. \& Spach

Hypericum orientale L.

Hypericum orientale $\mathrm{L}$.

Hypericum orientale $\mathrm{L}$.

Hypericum barbatum Jacq.

Hypericum barbatum Jacq.

Hypericum montbretii Spach

Hypericum perfoliatum

Hypericum richeri subsp. burseri (DC.) Nyman

Hypericum richeri subsp. burseri (DC.) Nyman

Hypericum richeri subsp. grisebachii Nyman

Hypericum rochelii Griseb. \& Schenk

Hypericum rumeliacum Boiss.

Hypericum elodeoides Choisy

Hypericum elodes L.

Hypericum elodes L.

Hypericum graveolens Buckley

Hypericum oaxacum Keller

Hypericum punctatum Lam.

Hypericum punctatum Lam.

Hypericum heterophyllum Vent.

Hypericum callithyrsum Coss

Hypericum helianthemoides (Spach) Boiss.

Hypericum hyssopifolium Vill.

Hypericum pseudolaeve N. Robson

Hypericum scabrum L.

Hypericum papuanum Ridl.

Hypericum peplidifolium A. Rich
Campylosporus C11 Campylosporus C3

Coridium

Coridium

Coridium

Coridium

C155

C23

$\mathrm{C} 24$

C256

Coridium

Coridium

Coridium

C200

Coridium

C255

C70

Coridium

AY5558

C107

Crossophyllum C37

Crossophyllum FJ694213

Crossophyllum FJ788905

Crossophyllum C244

Drosocarpium FJ694192

Drosocarpium C118

Drosocarpium C84

Drosocarpium C98

Drosocarpium C106

Drosocarpium C207

Burger 2422 (S)

Curcó s.n. (BCN)

Sanchez 5.1 (MA)

Sanchez 5.2 (MA)

Sanchez 169 (GB)

Ruiz s.n. (MA)

Sanchez 168 (GB)

Gadringer KRS5-6 (MA)

Crockett et al., 2004

(MA)

zler-Pilepic \& Blazina 2011

Kosuth et al., 2010

Sanchez 166 (MA)

\&lazina 2011

s.n. (GB)

Aedo 10350 (MA)

Aldasoro 3213 (MA)

Romero s.n. (MA)

Aldasoro 14189 (MA)

Drosocarpium C95

Drosocarpium C14

Elodeoida $\quad \mathrm{C} 135$

Elodes

C166

Quintanar 1283AQ (MA)

Emanuelsson 3001 (S)

Stainton 3562 (GB)

Devain s.n. (MA)

C69

Peralta s.n. (MA)

Graveolentia AY555843 Crockett et al., 2004

Graveolentia AY573003 Park \& Kim 2004

Graveolentia AY555844 Crockett et al., 2004

Graveolentia GU562400 Fazekas et al., 2010

Heterophylla C78 Nydegger 17659 (MA)

Hirtella

$\mathrm{C} 74$

C77

Hirtella

Hirtella

Hirtella

C81

Hirtella

C91

Humifusoideum C275

Humifusoideum C26
Pallares s.n. (MA)

Parisham s.n. (MA)

Sorger 82-71-10 (W)

Parisham s.n. (MA)

Guilli 99 (W)
Medina LM2961 (MA)

Aldasoro A10057 (MA)
Thulin 11038 (UPS)
Yemen, Socotra

Ethiopia, Harar prov. Somalia,

Greece, Creta

France, Alps Maritimes $\quad$ KC709319 KC709010 KC709178 KC708897

France, Alps Maritimes $\quad$ KC709320 KC709011 KC709179 KC708898

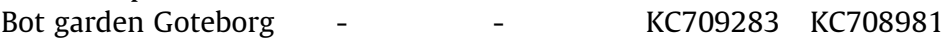

Greece, atenas

Bot garden Goteborg

Greece, Creta

Spain, Albacete Turkey,

Bot garden Goteborg

Bulgaria, Sofía

Bulgaria, Kosovo

Italy, Abruzzo

Spain, Leon

Spain, Santander

Bulgaria, Blagoevgrad Bulgaria, Asenovgrad Nepal, Gurjakhani Spain, Cantabria

Spain, Navarra

-

$-$

Turkey, Anatolia Spain, Almeria

Iran, Isfahan

Spain, Alava

Turkey, Karaagil

Iran, Isfahan

Papua New Guinea, E. Highlands

Ethiopia

AY555863* -

KC709394 KC709096 KC709244 KC708952

KC709309 KC708999 KC709169

KC709304 KC708994 KC709165 KC708886 KC709390 -

KC709416 - KC708966

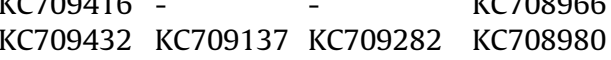

- KC709036 - -

AY555847* - - - -

KC709364 KC709064 KC709220 $\quad$ KC708932 KC709326 KC709017 KC709185 KC708904

$\begin{array}{llll}\text { FJ694213* - } & - & - \\ - & - & \text { FJ788905* - }\end{array}$

FJ694192* KC709134 -

KC709349 KC709048 KC709207 KC708922

KC709358 KC709057 KC709215 KC708927

KC709363 KC709063 KC709219 KC708931

KC709423 - KC747114 -

FJ694222* - $\quad-$

KC709355 -

KC709311 KC709002

KC709379 -

KC709393 KC709095 KC709243 KC708951

KC709340 KC709035 KC709198 KC708915

AY555843* -

AY573003* -

AY555844* -

KC709345 KC709043

KC709040 KC709202 KC708918

KC709344 KC709042 KC709204 KC708920

KC709347 KC709045 KC709206 KC708921

KC709441 KC709143 -

KC709353 KC709053 KC709211

- $\quad$ KC709142 KC709288 KC708985

KC709321 KC709012 KC709180 KC708899 


\begin{tabular}{|c|c|c|c|c|c|c|c|c|}
\hline \multirow[t]{2}{*}{ Specie } & \multirow[t]{2}{*}{ Section } & \multirow[t]{2}{*}{ ID } & \multirow[t]{2}{*}{ Voucher } & \multirow[t]{2}{*}{ Locality } & \multicolumn{4}{|c|}{ Genbank accession numbers } \\
\hline & & & & & & $\operatorname{trnL}-\operatorname{trnF}$ & psbA-trnH & trnS-trnG \\
\hline Hypericum peplidifolium A. Rich & Humifusoideum & $\mathrm{C} 27$ & Aldasoro A9971 (MA) & Ethiopia & KC709322 & KC709013 & KC709181 & KC708900 \\
\hline Hypericum scioanum Chiov. & Humifusoideum & $\mathrm{C} 29$ & Aldasoro A9957 (MA) & Ethiopia & КС709323 & KC709014 & KC709182 & KC708901 \\
\hline Hypericum scioanum Chiov. & Humifusoideum & $\mathrm{C} 30$ & Aldasoro A9991 (MA) & Ethiopia & KC709324 & KC709015 & KC709183 & KC708902 \\
\hline Hypericum asahinae Makino & Hypericum & AY572997 & Park \& Kim 2004 & - & AY572997* & - & - & - \\
\hline Hypericum attenuatum Fisch. ex Choisy & Hypericum & AY572993 & Park \& Kim 2004 & - & AY572993* & - & - & - \\
\hline Hypericum attenuatum Fisch. ex Choisy & Hypericum & AY572995 & Park \& Kim 2004 & - & AY572995* & - & - & - \\
\hline Hypericum chejuense Park \& Kim & Hypericum & AY572996 & Park \& Kim 2004 & - & AY572996* & - & - & - \\
\hline Hypericum elegans Stephan ex Willd. & Hypericum & C71 & Cernoch s.n. (MA) & Bulgaria, Haskovo & - & KC709037 & КC709199 & KC708916 \\
\hline Hypericum erectum Thunb. ex Murray & Hypericum & AY572991 & Park \& Kim 2004 & - & AY572991* & - & - & - \\
\hline Hypericum erectum Thunb. ex Murray & Hypericum & FJ788904 & Kosuth et al., 2010 & - & - & - & FJ788904* & - \\
\hline Hypericum erectum Thunb. ex Murray & Hypericum & C202 & García MAG 4071 (MA) & $\begin{array}{l}\text { South Korea, Jeollabuk- } \\
\text { do }\end{array}$ & KC709418 & KC709119 & KC709265 & KC708967 \\
\hline Hypericum formosum Kunth. & Hypericum & $\mathrm{C} 175$ & Merrill 12606 (MO) & USA, Colorado & KC709400 & KC709102 & KC709250 & KC708957 \\
\hline Hypericum hakonense Franchet \& Savat. & Hypericum & AY573000 & Park \& Kim 2004 & - & AY573000* & - & - & - \\
\hline Hypericum kamtschaticum Ledeb. & Hypericum & AY572992 & Park \& Kim 2004 & - & AY572992* & - & - & - \\
\hline Hypericum kamtschaticum Ledeb. & Hypericum & FJ793044 & Hazler-Pilepic \& Blazina 2011 & - & FJ793044* & - & - & - \\
\hline Hypericum kamtschaticum Ledeb. & Hypericum & 83758492 & Senni et al., 2005 & - & - & $83758492 *$ & - & - \\
\hline Hypericum kamtschaticum Ledeb. & Hypericum & 83758494 & Senni et al., 2005 & - & - & $83758494^{*}$ & - & - \\
\hline Hypericum kinashianum Koidz. & Hypericum & AY573001 & Park \& Kim 2004 & - & AY573001* & - & - & - \\
\hline Hypericum maculatum Crantz & Hypericum & C96 & Aedo CA9479 (MA) & Andorra & KC709356 & KC709055 & KC709213 & KC708925 \\
\hline $\begin{array}{l}\text { Hypericum maculatum subsp. maculatum } \\
\text { Crantz }\end{array}$ & Hypericum & C206 & Aldasoro 14182 (MA) & Spain, Santander & KC709422 & KC709123 & KC709269 & KC708970 \\
\hline Hypericum oliganthum Franchet \& Savat. & Hypericum & AY573005 & Park \& Kim 2004 & - & AY573005* & - & - & - \\
\hline Hypericum ovalifolium Koidz. & Hypericum & AY572998 & Park \& Kim 2004 & - & AY572998* & & - & - \\
\hline Hypericum perforatum L. & Hypericum & $\mathrm{C} 178$ & Schmidt 1508 (MO) & USA, Pennsylvania & KC709403 & KC709105 & KC709253 & KC708959 \\
\hline Hypericum perforatum L. & Hypericum & $\mathrm{C} 22$ & Sanchez 1 (MA) & Spain, Tarragona & KC709318 & KC709009 & KC709177 & KC708896 \\
\hline Hypericum perforatum L. & Hypericum & $\mathrm{C} 47$ & Tauleigne s.n. (MA) & Portugal, Baixo Alentejo & KC709332 & KC709023 & KC709191 & - \\
\hline Hypericum perforatum L. & Hypericum & C56 & Tauleigne s.n. (MA) & Portugal, Vinuoso & KC709333 & KC709024 & KC709192 & - \\
\hline Hypericum pseudopetiolatum Keller & Hypericum & AY573002 & Park \& Kim 2004 & - & AY573002* & - & - & - \\
\hline Hypericum scouleri Hook. & Hypericum & $\mathrm{C} 80$ & Twisselmann 11364 (MA) & USA, Tulare & KC709346 & KC709044 & KC709205 & - \\
\hline Hypericum sikokumontanum Makino & Hypericum & AY572999 & Park \& Kim 2004 & - & AY572999* & - & - & - \\
\hline Hypericum tetrapterum Fries & Hypericum & FJ694224 & Hazler-Pilepic \& Blazina 2011 & & FJ694224* & - & - & - \\
\hline Hypericum tetrapterum Fries & Hypericum & FJ788897 & Kosuth et al., 2010 & - & - & - & FJ788897* & - \\
\hline Hypericum tetrapterum Fries & Hypericum & $\mathrm{C} 21$ & Sanchez 2 (MA) & Spain, Tarragona & КC709317 & KC709008 & KC709176 & KC708895 \\
\hline Hypericum triquetrifolium Turra & Hypericum & C39 & Aldasoro A9795 (MA) & Turkey & KC709328 & KC709019 & KC709187 & KC708906 \\
\hline Hypericum undulatum Schousboe ex Willd. & Hypericum & C156 & Vigo s.n. (BCN) & Spain, Soria & - & KC709089 & - & - \\
\hline Hypericum undulatum Schousboe ex Willd. & Hypericum & C99 & Serra 6034 (MA) & Spain, Oviedo & KC709359 & KC709058 & KC709216 & KC708928 \\
\hline Hypericum vaniotii Lev. & Hypericum & AY572994 & Park \& Kim 2004 & - & AY572994* & - & - & - \\
\hline Hypericum yezoense Maxim. & Hypericum & FJ793046 & Hazler-Pilepic \& Blazina 2011 & - & FJ793046* & - & - & - \\
\hline Hypericum yezoense Maxim. & Hypericum & AY573004 & Park \& Kim 2004 & - & AY573004* & - & - & - \\
\hline Hypericum xylosteifolium (Spach) N. Robson & Inodora & $\mathrm{C} 274$ & Sorger $69-23-28(\mathrm{~W})$ & Turkey, Steilhange & - & - & KC709287 & KC708984 \\
\hline $\begin{array}{l}\text { Hypericum monanthemum Hook. F. \& } \\
\text { Thomsom ex Dyer }\end{array}$ & Monanthema & $\mathrm{C} 283$ & Larsen 46519 (AAU) & Thailand, ChiangMai & KC709443 & KC709147 & - & - \\
\hline Hypericum wightianum Wall. & Monanthema & $\mathrm{C} 273$ & Kingdom-Ward 22448 (W) & Burma, Mindat & - & - & KC709286 & KC708983 \\
\hline
\end{tabular}

Hypericum peplidifolium A. Rich

Hypericum attenuatum Fisch. ex Choisy 列

Hypericum formosum Kunth

Hypericum hakonense Franchet \& Savat.

Hypericum kamtschaticum Ledeb.

icum Ledeb.

Crant

Hypericum pseudopetiolatum Keller

onanthema 
Hypericum adpressum W. Barton Hypericum apocynifolium Small

Hypericum brachyphyllum (Spach) Steud.

Hypericum brachyphyllum (Spach) Steud.

Hypericum buckleyi Curtis

Hypericum chapmanii Adams

Hypericum cistifolium Lam.

Hypericum cistifolium Lam.

Hypericum crux-andreae (L) Crantz

Hypericum crux-andreae (L) Crantz

Hypericum densiflorum Pursh

Hypericum densiflorum Pursh

Hypericum dolabriforme Vent.

Hypericum ellipticum Hook.

Hypericum fasciculatum Lam.

Hypericum fasciculatum Lam.

Hypericum fasciculatum Lam.

Hypericum frondosum Michaux

Hypericum galioides Lam.

Hypericum galioides Lam.

Hypericum hypericoides (L.) Crantz

Hypericum hypericoides (L.) Crantz

Hypericum kalmianum L.

Hypericum kalmianum L.

Hypericum lissophloeus P. Adams

Hypericum lissophloeus P. Adams

Hypericum lloydii (Svenson) P. Adams

Hypericum lobocarpum Gattinger

Hypericum microsepalum (Torrey \& Gray) Gray ex Watson

Hypericum myrtifolium Lam.

Hypericum nitidum Lam.

Hypericum nudiflorum Michaux

Hypericum prolificum L.

Hypericum prolificum $\mathrm{L}$.

Hypericum sphaerocarpum Michaux

Hypericum tenuifolium Pursh

Hypericum tenuifolium Pursh

Hypericum tetrapetalum Lam.

Hypericum tetrapetalum Lam.

Hypericum humifusum L.

Hypericum humifusum L.

Hypericum humifusum L.

Hypericum linariifolium Vah

Hypericum linariifolium Vahl

Hypericum linariifolium Vahl

Hypericum olympicum L.

Hypericum olympicum L.
Myriandra

Myriandra

Myriandra

Myriandra

Myriandra

Myriandra

Myriandra

Myriandra

Myriandra

Myriandra

Myriandra

Myriandra

Myriandra

Myriandra

Myriandra

Myriandra

Myriandra

Myriandra

Myriandra

Myriandra

Myriandra

Myriandra

Myriandra

Myriandra

Myriandra

Myriandra

Myriandra

Myriandra

Myriandra

Myriandra

Myriandra

Myriandra

Myriandra

Myriandra

Myriandra

Myriandra

Myriandra

Myriandra

Myriandra

Oligostema

Oligostema

Oligostema

Oligostema

Oligostema

Oligostema

Olympia

Olympia
AY555865 Crockett et al., 2004

AY555883 Crockett et al., 2004

AY555870 Crockett et al., 2004

C181 Miller 8438 (MO)

AY555880 Crockett et al., 2004

AY555869 Crockett et al., 2004

C176 Bradley 1186 (MO)

C177 Miller 8393 (MO)

AY555874 Crockett et al., 2004

C174 Miller 8455 (MO)

AY555886 Crockett et al., 2004

C73 Thomas 97505 (MA)

AY555889 Crockett et al., 2004

C5 Schepanek 6623 (UPS)

AY555868 Crockett et al., 2004

C173 Bradley 1187 (MO)

C76 Carrasco s.n. (MA)

AY555887 Crockett et al., 2004

AY555864 Crockett et al., 2004

C133 Boufford 5149 (GB)

C132 Vicent $4291(\mathrm{CB})$

C185 Miller 8447 (MO)

FJ694209 Hazler-Pilepic \& Blazina 201

FJ788896 Kosuth et al., 2010

AY555885 Crockett et al., 2004

C134 Godfrey 61554 (GB)

AY555867 Crockett et al, 2004

AY555876 Crockett et al., 2004

AY555877 Crockett et al., 2004

AY555875 Crockett et al., 2004

AY555871 Crockett et al., 2004

AY555888 Crockett et al., 2004

C182 Nye 243 (MO)

C97 Ahles 87220 (MA)

AY555878 Crockett et al., 2004

AY555872 Crockett et al., 2004

C13 Bradley 3345 (S)

AY555882 Crockett et al., 2004

C122 Vicent 5153 (GB)

FJ788903 Kosuth et al., 2010

C201 Ruiz s.n. (MA)

C204 Aldasoro 14208 (MA)

C63 Amaraz s.n. (MA)

C165 Gómiz s.n. (BC)

C46 Tauleigne s.n. (MA)

C199 Ruiz s.n. (MA)

C57 Sanchez AS9 (MA)

AY555865*

AY555883* -

AY555870* -

USA, Florida $\quad$ KC709405 KC709107 KC709255 KC708961

AY555869*-

USA, Florida

USA, Florida

KC709402 KC709104 KC709252

KC709402 KC709104 KC709252 -

KC709399 KC709101 KC709249

AY555886* -

USA, Ashley

KC709039 KC709201 -

AY555889* -

Canada, McAdam Parish KC709306 KC708996 KC709167 KC708887

$\begin{array}{lllll} & \text { USA, Florida } & \text { KC709398 } & \text { KC709100 } & \text { KC709248 } \\ \text { KC708956 }\end{array}$

Cuba, Santiago de Cuba KC709343 KC709041 KC709203 KC708919

$\begin{array}{llllll}\text { Georgia, Evans } & \text { KC709377 } & \text { KC709077 } & \text { KC709230 KC708937 }\end{array}$

USA, N Carolina, Union KC709376 KC709076 KC709229 KC708936

USA, Florida $\quad$ KC709407 KC709109 KC709257 KC708963 FJ694209* -

FJ788896*

USA, Florida, Bay

AY555885* -

KC709378 KC709078 KC708938

AY555867* -

AY555876*

AY555877* -

AY555875* -

AY555871* -

AY555888* -

USA, Missouri

USA, Massachuset

KC709406 KC709108 KC709256 KC708962

KC709357 KC709056 KC709214 KC708926

AY555878*

AY555872* -

USA, North Carolina $\quad$ KC709310 KC709001 KC709170 KC708890

USA, Florida, Levy

KC709371 KC709072 KC709226

- FJ788903*

Morroco, Tetuan

Spain, Santander

Spain, Cáceres

Spain, Leon

KC709417 KC709118 KC709264

KC709420 KC709121 KC709267 -

KC709031 -

KC709094 KC709242

Portugal, Baixo Alentejo KC709331 KC709022 KC709190 KC708909

Greece, Laconia $\quad$ KC709415 KC709117 KC709263 KC708965

Royal Bot garden Madrid KC709334 KC709025 KC709193 KC708910

(continued on next page) 


\begin{tabular}{|c|c|c|c|c|c|c|c|c|}
\hline \multirow[t]{2}{*}{ Specie } & \multirow[t]{2}{*}{ Section } & \multirow[t]{2}{*}{ ID } & \multirow[t]{2}{*}{ Voucher } & \multirow[t]{2}{*}{ Locality } & \multicolumn{4}{|c|}{ Genbank accession numbers } \\
\hline & & & & & ITS & $\operatorname{trnL}-\operatorname{trn} F$ & psbA-trnH & trnS-trnG \\
\hline Hypericum polyphyllum Boiss. \& Balansa & Olympia & FJ694216 & Hazler-Pilepic \& Blazina 2011 & & FJ694216* & - & - & - \\
\hline Hypericum balearicum L. & Psorophytum & C40 & Saez 5006 (MA) & Spain, Mallorca & KC709329 & KC709020 & KC709188 & KC708907 \\
\hline Hypericum balearicum L. & Psorophytum & C61 & Sanchez 13 (MA) & Royal Bot garden Madrid & KC709338 & KC709029 & KC709197 & KC708914 \\
\hline Hypericum ascyron L. & Roscyna & FJ694189 & Hazler-Pilepic \& Blazina 2011 & & FJ694189* & - & - & - \\
\hline Hypericum ascyron subsp ascyron L. & Roscyna & C44 & MAGarcía 4059 (MA) & $\begin{array}{l}\text { South Korea, Jeollakbuk- } \\
\text { do }\end{array}$ & КС709330 & KC709021 & KC709189 & KC708908 \\
\hline Hypericum sampsonii Hance & Sampsonia & AY573011 & Park \& Kim 2004 & - & AY573011* & - & - & - \\
\hline Hypericum confertum Choisy & Taeniocarpium & $\mathrm{C} 138$ & Lindberg s.n. (GB) & Cyprus, Mt. Troodos & КC709381 & KC709080 & KC709232 & KC708940 \\
\hline Hypericum hirsutum L. & Taeniocarpium & FJ694203 & Hazler-Pilepic \& Blazina 2011 & - & FJ694203* & - & - & - \\
\hline Hypericum hirsutum L. & Taeniocarpium & C59 & Sanchez 11 (MA) & Royal Bot garden Madrid & KC709336 & KC709027 & KC709195 & KC708912 \\
\hline Hypericum linarioides Bosse & Taeniocarpium & C88 & Aldasoro 2667 (MA) & Turkey, Sakaltutan & KC709352 & KC709051 & KC709210 & KC708923 \\
\hline Hypericum nummularioides Trautv. & Taeniocarpium & C243 & Sanchez 164 (MA) & Bot garden Goteborg & - & KC709133 & KC709279 & - \\
\hline Hypericum nummularium L. & Taeniocarpium & C101 & Jauregui s.n. (MA) & Spain, Navarra & КC709360 & KC709059 & KC709217 & - \\
\hline Hypericum nummularium L. & Taeniocarpium & C205 & Aldasoro 14179 (MA) & Spain, Santander & КC709421 & KC709122 & KC709268 & KC708969 \\
\hline Hypericum pulchrum L. & Taeniocarpium & FJ694219 & Hazler-Pilepic \& Blazina 2011 & - & FJ694219* & - & - & - \\
\hline Hypericum venustum Fengl & Taeniocarpium & C280 & Sorger 81-27-21 (W) & Turkey, Hakkari & - & KC709145 & - & - \\
\hline Hypericum geminiflorum Hemsley & Takasagoya & $\mathrm{C} 12$ & Chung $1266(S)$ & $\begin{array}{l}\text { China, Taiwan, Pingtung } \\
\text { Hsien }\end{array}$ & HM162838 & KC709000 & - & - \\
\hline Hypericum thasium Griseb. & Thasia & $\mathrm{C} 278$ & Rechinger $45280(\mathrm{~W})$ & Greece, thasos & - & KC709144 & - & - \\
\hline Hypericum pallens Banks \& Solander & Triadenioides & $\mathrm{C} 253$ & Sanchez 167 (MA) & Bot garden Goteborg & - & - & KC709281 & - \\
\hline Hypericum pallens Banks \& Solander & Triadenioides & AY555848 & Crockett et al., 2004 & - & AY555848* & - & - & - \\
\hline Hypericum scopulorum Balf. f. & Triadenioides & C169 & Aldasoro 14644 (MA) & $\begin{array}{l}\text { Yemen, Socotra, } \\
\text { Magarhar }\end{array}$ & KC709395 & KC709097 & KC709245 & KC708953 \\
\hline Hypericum tortuosum Balf. f. & Triadenioides & $\mathrm{C} 170$ & Aldasoro 14645 (MA) & Yemen, Socotra & КC709396 & KC709098 & KC709246 & KC708954 \\
\hline Hypericum boreale (Britton) Bickn. & Trigynobrathys & AY573026 & Park \& Kim 2004 & - & AY573026* & - & - & - \\
\hline Hypericum boreale (Britton) Bickn. & Trigynobrathys & $\mathrm{C} 130$ & Ahles 86328 (GB) & USA, Massachuset & KC709374 & KC709074 & KC709228 & KC708935 \\
\hline Hypericum brevistylum Choisy & Trigynobrathys & AY573019 & Park \& Kim 2004 & - & AY573019* & - & - & - \\
\hline Hypericum brevistylum Choisy. & Trigynobrathys & C317 & Hilpold 11745 (BOZ) & Peru, Cuzco & KC709452 & KC709163 & - & - \\
\hline Hypericum brevistylum Choisy & Trigynobrathys & C318 & Hilpold 11413 (BOZ) & Peru, Ancash & КC709453 & KC709164 & - & - \\
\hline Hypericum canadense $\mathrm{L}$. & Trigynobrathys & C259 & Brisson 12774 (GB) & Canada, Lac Aylmer & КC709434 & KC709139 & - & KC708982 \\
\hline Hypericum gramineum G. Foster & Trigynobrathys & EU352256 & Heenan 2008 & - & EU352256* & - & - & - \\
\hline Hypericum gramineum G. Foster & Trigynobrathys & EU352257 & Heenan 2008 & - & EU352257* & - & - & - \\
\hline Hypericum japonicum Thunb. ex Murray & Trigynobrathys & AY573025 & Park \& Kim 2004 & - & AY573025* & - & - & - \\
\hline Hypericum japonicum Thunb. ex Murray & Trigynobrathys & FJ980417 & Chen \& Han, unpublish & - & FJ980417* & - & - & - \\
\hline Hypericum japonicum Thunb. ex Murray & Trigynobrathys & GQ435379 & Chen et al., 2010 & - & - & - & GQ435379* & - \\
\hline Hypericum jeongjocksanense Park \& Kim & Trigynobrathys & AY573023 & Park \& Kim 2004 & - & AY573023* & - & - & - \\
\hline Hypericum lalandii Choisy & Trigynobrathys & $\mathrm{C} 128$ & Dahlstrand 2633 (GB) & $\begin{array}{l}\text { South Africa, E. Cape } \\
\text { Provice }\end{array}$ & KC709373 & KC709073 & KC709227 & - \\
\hline Hypericum lalandii Choisy & Trigynobrathys & C248 & Dahlstrand 1102 (GB) & South Africa, Transvaal & KC709431 & KC709135 & - & - \\
\hline Hypericum laxum (Bl.) Koidz. & Trigynobrathys & AY573024 & Park \& Kim 2004 & - & AY573024* & - & - & - \\
\hline Hypericum majus (A. Gray) Britton & Trigynobrathys & C85 & Rastetter s.n. (MA) & France, Haute-Saone & KC709350 & КC709049 & KC709208 & - \\
\hline Hypericum mutilum L. & Trigynobrathys & DQ006195 & Kress et al., 2005 & - & - & - & DQ006195* & - \\
\hline Hypericum mutilum L. & Trigynobrathys & C164 & Lazare s.n. (BC) & France, Landes & КC709392 & KC709093 & KC709241 & KC708950 \\
\hline Hypericum mutilum subsp. boreale (Britton) & Trigynobrathys & C179 & Schmidt 1488 (MO) & USA, Ohio & KC709404 & KC709106 & KC709254 & KC708960 \\
\hline
\end{tabular}

Hypericum polyphyllum Boiss. \& Balansa

Hypericum ascyron subsp ascyron L.

Hypericum sampsonii Hance choisy

Hypericum linarioides Bosse

Hypericum scopulorum Balf. f.

yypericum tortuosum Balf. f.

Hypericum canadense L.

Hypericum japonicum Thunb. ex Murray

Hypericum japonicum Thunb. ex Murray

Hypericum jeongjocksanense Park \& Kim

J. M. Gillett
Taeniocarpium C101

niocarpium C205

Taeniocarpium FJ694219

Takasagoya $\quad \mathrm{C} 12$

Thasia

Triadenioides $\mathrm{C}$

riadenioides $\mathrm{C}$

rigynobrathys AY573

Trigynobrathys C318

Hilpold 11413 (BOZ)

Brisson 12774 (GB)

Trigynobrathys GQ435379 Chen et al. 2010

Trigynobrathys AY573023 Park \& Kim 2004

Dahlstrand 1102 (GB)

Trigynobrathys C85

Schmidt 1488 (MO) 
Hypericum myrianthum subsp.

tamariscinum (C\&S) Robson

Hypericum rigidum A. St. Hil.

Hypericum setosum $\mathrm{L}$.

Trigynobrathys C264

Pedersen 15904 (GB)

Trigynobrathys AY573021 Park \& Kim 2004

Trigynobrathys AY573020 Park \& Kim 2004

Hypericum silenoides subsp. silenoides Juss. Trigynobrathys C67 Basualto (MA)

Hypericum ternum A. St. Hil.

Hypericum canariense $\mathrm{L}$.

Trigynobrathys AY573022 Park \& Kim 2004

Hypericum canariense $\mathrm{L}$.

Webbia C148 Aldasoro A10304 (MA)

C151 Aldasoro A10312 (MA)

\& McClintock

Thornea matudae (Lundell) Breedl. \&

McClintock

Triadenum fraseri (Spach) Gleason

Triadenum petiolatum Hook f. \& Thomson ex -

Dyer

\section{Vismieae}

Harungana madagascarensis Lam. ex Poir.

Psorospermum senegalense Spach

Vismia glaziovii Ruhland

Vismia rubescens Oliv.

AY573028 Park \& Kim 2004

AY573027 Park \& Kim 2004

C282 Ford $547(\mathrm{~W})$

C16 Correll $35026(\mathrm{~S})$

C105 Fernandez Casas s.n. (MA)

C109 Duvale 549 (MA)

Fuentes 10934 (MO)

$\begin{array}{ll}\text { C190 } & \text { Fuentes 10934 (MO) } \\ \text { C192 } & \text { Niangadouma } 374(\mathrm{MO})\end{array}$

Cratoxyleae

Eliea articulata (Lam.) Cambess
C189
Brasil, Restinga Seca

$-$

Chile, VIII region,

Concepcion

Spain, Tenerife

Spain, Tenerife

Canada, Manitoba USA, Texas

Equatorial Guinea, Bioko KC709362 KC709062 -

KC708930

Mali, Korofing National

KC709066 KC709222 -

Park

Bolivia, La Paz

KC709410 KC709112 -

KC708964

Gabon, Haute-Ogooue KC709411 -

KC709409 KC709111 KC709259 -

Madagascar, 


\section{Appendix B. Supplementary material}

Supplementary data associated with this article can be found, in the online version, at http://dx.doi.org/10.1016/j.ympev.2013.02. 007.

\section{References}

Aguilar, J.F., Rosselló, J.A., Feliner, G.N., 1999. Molecular evidence for the compilospecies model of reticulate evolution in Armeria (Plumbaginaceae). Systematic Biology 48, 735-754.

Akaike, H., 1973. Information theory and an extension of the maximum likelihood principle. In: Kiado, A. (Ed.), Second International Symposium on Information Theory, Budapest, pp. 267-281.

Álvarez, I., Wendel, J.F., 2003. Ribosomal ITS sequences and plant phylogenetic inference. Molecular Phylogenetics and Evolution 29, 417-434.

Arbuzova, O., 2005. Hypericum L. In: Budantsev, L. (Ed.), Iskopaemye tsvetkovye rastenija Rossii i sopredel'nyh gosudarstv [Fossil Flowering Plants of Russia and Adjacent Countries]. Izdatelstvo Nauka Leningradskoe otd-nie, 1974-. Leningrad.

Barnes, J., Anderson, L.A., Phillipson, D.J., 2001. St. John's wort (Hypericum perforatum L.): a review of its chemistry, pharmacology and clinical properties. Journal of Pharmacy and Pharmacology 53, 583-600.

Bentham, G., 1862. Hypericineae and Guttiferae. In: Bentham, G., Hooker, J.D. (Eds.), Genera Plantarum, vol. 1, London, pp. 163-177.

Borsch, T., Quandt, D., 2009. Mutational dynamics and phylogenetic utility of noncoding chloroplast DNA. Plant Systematics and Evolution 282, 169-199.

Brown, J.M., Hedtke, S.M., Lemmon, A.R., Lemmon, E.M., 2010. When trees grow too long: investigating the causes of highly inaccurate bayesian branch-length estimates. Systematic Biology 59, 145-161.

Brundin, L., 1966. Transantarctic relationships and their significance, as evidenced by chironomid midges: with a monograph of the subfamilies Podonominae and Aphroteniinae and the Austral Heptagyiae. Kungliga Svenska Vetenskapsakademien Handlingar 11, 1-472.

Carine, M.A., Christenhusz, M.J.M., 2010. About this volume: the monograph of Hypericum by Norman Robson. Phytotaxa 4, 1-4.

Castresana, J., 2000. Selection of conserved blocks from multiple alignments for their use in phylogenetic analysis. Molecular Biology and Evolution 17, 540552.

Choisy, J.D., 1821. Prodromus d'une monographic de la famille des Hypericacees, Geneva.

Coetzee, J.A., 1993. African flora since the terminal Jurassic. In: Goldblatt, P. (Ed.), Biological Relationships between Africa and South America. Yale University Press, New Haven, pp. 37-61.

Crockett, S.L., Douglas, A.W., Scheffler, B.E., Khan, I.A., 2004. Genetic profiling of Hypericum (St. John's Wort) species by nuclear ribosomal ITS sequence analysis. Planta Medica 70, 929-935.

Davis, C.C., Bell, C.D., Mathews, S., Donoghue, M.J., 2002. Laurasian migration explains Gondwanan disjunctions: evidence from Malpighiaceae. Proceedings of the National Academy of Sciences of the United States of America 99, 68336837.

Davis, C.C., Fritsch, P.W., Bell, C.D., Mathews, S., 2004. High-latitude tertiary migrations of an exclusively tropical clade: evidence from Malpighiaceae. International Journal of Plant Sciences, 165.

Davis, C.C., Webb, C.O., Wurdack, K.J., Jaramillo, C.A., Donoghue, M.J., 2005. Explosive radiation of malpighiales supports a mid-Cretaceous origin of modern tropical rain forests. American Naturalist 165, E36-E65.

Donoghue, M.J., Moore, B.R., 2003. Toward an integrative historical biogeography. Integrative and Comparative Biology 43, 261-270.

Donoghue, M.J., Smith, S.A., 2004. Patterns in the assembly of temperate forests around the Northern Hemisphere. Philosophical Transactions of the Royal Society of London B Biological Sciences 359, 1633-1644.

Doyle, J.J., 1992. Gene trees and species trees: molecular systematics as onecharacter taxonomy. Systematic Botany 17, 144-163.

Drummond, A.J., Rambaut, A., 2007. BEAST: Bayesian evolutionary analysis by sampling trees. Bmc Evolutionary Biology 7, 8.

Goudie, A.S., 2005. The drainage of Africa since the Cretaceous. Geomorphology 67, 437-456.

Greiner, S., Rauwolf, U., Meurer, J., Herrmann, R.G., 2011. The role of plastids in plant speciation. Molecular Ecology 20, 671-691.

Gronlie, G., 1979. Tertiary paleogeography of the Norwegian Greenland Sea. Norsk Polarinstitutt Skrifter 170, 49-61.

Gustafsson, C., Persson, C., 2002. Phylogenetic relationships among species of the neotropical genus Randia (Rubiaceae, gardenieae) inferred from molecular and morphological data. Taxon 51, 661-674.

Hamilton, M.B., 1999. Four primer pairs for the amplification of chloroplast intergenic regions with intraspecific variation. Molecular Ecology 8, 521-523.

Heenan, P.B., 2008. Three newly recognised species of Hypericum (Clusiaceae) from New Zealand. New Zealand Journal of Botany 46, 547-558.

Hennig, W., 1966. Phylogelletic Systelllotics. University of Illinois Press, Urbana.

Ho, S.Y.W., Phillips, M.J., 2009. Accounting for calibration uncertainty in phylogenetic estimation of evolutionary divergence times. Systematic Biology 58, 367-380.
Hoorn, C., Wesselingh, F.P., Ter Steege, H., Bermudez, M.A., Mora, A., Sevink, J., et al., 2010. Amazonia through time: Andean uplift, climate change, landscape evolution, and biodiversity. Science 330, 927-931.

Huelsenbeck, J.P., Bollback, J.P., 2001. Empirical and hierarchical Bayesian estimation of ancestral states. Systematic Biology 50, 351-366.

Jacobs, B.F., 2004. Palaeobotanical studies from tropical Africa: relevance to the evolution of forest, woodland and savannah biomes. Philosophical Transactions of the Royal Society B: Biological Sciences 359, 1573-1583.

Janeček, Š., Hrázský, Z., Bartoš, M., Brom, J., Reif, J., Hořák, D., et al., 2007. Importance of big pollinators for the reproduction of two Hypericum species in Cameroon, West Africa. African Journal of Ecology 45, 607-613.

Kass, R.E., Raftery, A.E., 1995. Bayes factors. Journal of the American Statistical Association 90, 773-795.

Katoh, K., Toh, H., 2008. Recent developments in the MAFFT multiple sequence alignment program. Briefings in Bioinformatics 9, 286-298.

Katoh, K., Misawa, K., Kuma, K.I., Miyata, T., 2002. MAFFT: a novel method for rapid multiple sequence alignment based on fast Fourier transform. Nucleic Acids Research 30, 3059-3066.

Kay, K.M., Whittall, J.B., Hodges, S.A., 2006. A survey of nuclear ribosomal internal transcribed spacer substitution rates across angiosperms: an approximate molecular clock with life history effects. BMC Evolutionary Biology 6, 36. http:// dx.doi.org/10.1186/1471-2148-6-36.

Keller, R., 1925. Hypericum. In: Engler, A., Prantl, K. (Eds.), Die natürlichen Pflanzenfamilien. Engelmann, Leipzig, pp. 175-183.

Keller, R., 1983. Hypericum. In: Engler, A., Prantl, K. (Eds.), Die natürlichen Pflanzenfamilien Leipzig, pp. 208-215.

Kibbe, W.A., 2007. OligoCalc: an online oligonucleotide properties calculator Nucleic Acids Research 35, W43-W46.

Kimura, Y., 1951. Hypericaceae. In: Nakai, T., Honda, M. (Eds.), Nova Flora Japonica, Tokyo, Sanseido.

Krijgsman, W., Hilgen, F.J., Raffi, I., Sierro, F.J., Wilson, D.S., 1999. Chronology, causes and progression of the Messinian salinity crisis. Nature 400, 652-655.

Lemey, P., Rambaut, A., Drummond, A.J., Suchard, M.A., 2009. Bayesian phylogeography finds its roots. PLoS Computational Biology 5.

Lemmon, A.R., Brown, J.M., Stanger-Hall, K., Lemmon, E.M., 2009. The effect of missing data on phylogenetic estimates obtained by maximum likelihood and Bayesian interference. Systematic Biology 58, 130-145.

Lewis, P.O., 2001. A likelihood approach to estimating phylogeny from discrete morphological data. Systematic Biology 50, 921-925.

Litsios, G., Salamin, N., 2012. Effects of phylogenetic signal on ancestral state reconstruction. Systematic Biology 61, 533-538.

Marshall, D.C., 2010. Cryptic failure of partitioned bayesian phylogenetic analyses: lost in the land of long trees. Systematic Biology 59, 108-117.

Marshall, D.C., Simon, C., Buckley, T.R., 2006. Accurate branch length estimation in partitioned Bayesian analyses requires accommodation of among-partition rate variation and attention to branch length priors. Systematic Biology 55, 993 1003.

McKenna, M.C., 1983. Cenozoic paleogeography of North Atlantic land bridges. Structure and Development of the Greenland-Scotland Ridge, pp. 351-399.

Medgyesy, P., Fejes, E., Maliga, P., 1985. Interspecific chloroplast recombination in a Nicotiana somatic hybrid. Proceedings of the National Academy of Sciences 82 6960-6964.

Meseguer, A.S., Sanmartín, I., 2012. Paleobiology of the genus Hypericum (Hypericaceae): a survey of the fossil record and its palaeogeographic implications. Anales del Jardin Botanico de Madrid 69, 97-106.

Meulenkamp, J.E., Sissingh, W., 2003. Tertiary palaeogeography and tectonostratigraphic evolution of the Northern and Southern Peri-Tethys platforms and the intermediate domains of the African-Eurasian convergent plate boundary zone. Palaeogeography, Palaeoclimatology, Palaeoecology 196, 209-228.

Michenea, C., Jacques, F., Thierry, P., 2006. Bird pollination in an angraecoid orchid on Reunion Island (Mascarene Archipelago, Indian Ocean). Annals of Botany 97 965-974.

Müller, K., 2005. SeqState: primer design and sequence statistics for phylogenetic DNA datasets. Applied Bioinformatics 4, 65-69.

Nürk, N.M., Blattner, F.R., 2010. Cladistic analysis of morphological characters in Hypericum (Hypericaceae). Taxon 59, 1495-1507.

Nürk, N.M., Madriñán, S., Carine, M.A., Chase, M.W., Blattner, F.R., 2012. Molecular phylogenetics and morphological evolution of St. John's wort (Hypericum; Hypericaceae). Molecular Phylogenetics and Evolution.

Nylander, J.A.A., 2004. MrModeltest v2. Program distributed by the author Evolutionary Biology Centre, Uppsala University.

Nylander, J.A.A., Ronquist, F., Huelsenbeck, J.P., Nieves-Aldrey, J.L., 2004. Bayesian phylogenetic analysis of combined data. Systematic Biology 53, 47-67.

Nylander, J.A.A., Wilgenbusch, J.C., Warren, D.L., Swofford, D.L., 2008. AWTY (are we there yet?): a system for graphical exploration of MCMC convergence in Bayesian phylogenetics. Bioinformatics 24, 581-583.

Park, S., Kim, K., 2004. Molecular phylogeny of the genus Hypericum (Hypericaceae) from Korea and Japan: evidence from nuclear rDNA ITS sequence data. Journal of Plant Biology 47, 366-374.

Pilepić, K.H., Balić, M., Blažina, N., 2011. Estimation of phylogenetic relationships among some Hypericum (Hypericaceae) species using internal transcribed spacer sequences. Plant Biosystems 145, 81-87.

Plana, V., 2004. Mechanisms and tempo of evolution in the African GuineoCongolian rainforest. Philosophical Transactions of the Royal Society B: Biological Sciences 359, 1585-1594. 
Rambaut, A., 2002. Se-Al: Sequence Alignment Editor. <http://tree.bio.ed.ac.uk/ software/seal/>.

Rambaut, A., Charleston, M., 2001. TreeEdit: Phylogenetic Tree Editor v. 1.0 alpha 8. University of Oxford.

Rambaut, A., Drummond, A.J., 2009. Tracer, version 1.5, MCMC Trace Analysis Package. <http://tree.bio.ed.ac.uk/software/>.

Ree, R.H., Sanmartín, I., 2009. Prospects and challenges for parametric models in historical biogeographical inference. Journal of Biogeography 36, 1211-1220.

Renner, O., 1934. Die pflanzlichen Plastiden als selbständige Elemente der genetischen Konstitution. Berichte der mathemathisch-physikalischen Klasse der sächsischen Akademie der Wissenschaften zu Leibzig 86, 241-266.

Riegert, J., Fainová, D., Antczak, M., Sedláček, O., Hořák, D., Reif, J., et al., 2011. Food niche differentiation in two syntopic sunbird species: a case study from the Cameroon Mountains. Journal of Ornithology 152, 819-825.

Robson, N.K.B., 1977. Studies in the genus Hypericum L. (Guttiferae). 1. Infrageneric classification. Bulletin of the British Museum (Natural History), Botany Series 5 , 295-355.

Robson, N.K.B., 1981. Studies in the genus Hypericum L. (Guttiferae). 2. Characters of the genus. Bulletin of the British Museum (Natural History), Botany Series 8, $55-226$.

Robson, N.K.B., 1985. Studies in the genus Hypericum L. (Guttiferae). 3. Sections 1. Campylosporus to 6a. Umbraculoides. Bulletin of the British Museum (Natural History), Botany Series 12, 163-211.

Robson, N.K.B., 1987. Studies in the genus Hypericum L. (Guttiferae). 7. Section 29. Brathys (part 1). Bulletin of the British Museum (Natural History), Botany Series $16,1-106$.

Robson, N.K.B., 1990. Studies in the genus Hypericum L. (Guttiferae). 8. Sections 29. Brathys (part 2) and 30. Trigynobrathys. Bulletin of the British Museum (Natura History), Botany Series 20,1-151.

Robson, N.K.B., 1996. Studies in the genus Hypericum L. (Guttiferae). 6. Sections 20. Myriandra to 28. Elodes. Bulletin of the British Museum (Natural History), Botany Series 26, 75-217.

Robson, N.K.B., 2001. Studies in the genus Hypericum L. (Guttiferae). 4(1). Sections 7. Roscyna to 9. Hypericum sensu lato (part 1). Bulletin of the British Museum (Natural History), Botany Series 31, 37-88.

Robson, N.K.B., 2002. Studies in the genus Hypericum L. (Guttiferae).4(2). Section 9. Hypericum sensu lato (part 2): subsection 1. Hypericum series 1, Hypericum. Bulletin of the Natural History Museum, London (Botany) 32, 61-123.

Robson, N.K.B., 2006. Studies in the genus Hypericum L. (Clusiaceae). Section 9. Hypericum sensu lato (part 3): subsection 1. Hypericum series 2. Senanensia, subsection 2. Erecta and section 9b Graveolentia. Systematics and Biodiversity 4 19-98.

Robson, N.K.B., 2010a. Studies in the genus Hypericum L. (Hypericaceae). 5(1). Sections 10. Olympia to 15/16. Crossophyllum. Phytotaxa 4, 5-126.

Robson, N.K.B., 2010b. Studies in the genus Hypericum L. (Hypericaceae). 5(2). Section 17. Hirtella to 19. Coridium. Phytotaxa 4, 127-258.

Robson, N.K.B., 2012. Studies in the genus Hypericum L. (Hypericaceae) 9. Addenda, corrigenda, keys, lists and general discussion. Phytotaxa 72, 1-111.

Ronquist, F., 2004. Bayesian inference of character evolution. Trends in Ecology and Evolution 19, 475-481.

Ronquist, F., Sanmartín, I., 2011. Phylogenetic methods in historical biogeography. Annual Review of Ecology, Evolution, and Systematics.

Ronquist, F., Teslenko, M., Van Der Mark, P., Ayres, D.L., Darling, A., H $\sqrt{ }$ ohna, S. Larget, B., Liu, L., Suchard, M.A., Huelsenbeck, J.P., 2012. Mrbayes 3.2: efficient bayesian phylogenetic inference and model choice across a large model space. Systematic Biology 61, 539-542.

Rosenbaum, G., Lister, G.S., Duboz, C., 2002. Reconstruction of the tectonic evolution of the western Mediterranean since the Oligocene. Journal of the Virtua Explorer 8, 107-130.

Ruhfel, B.R., 2011. Systematics and Biogeography of the Clusioid Clade (Malpighiales). Harvard University, Cambridge, Massachusetts.

Ruhfel, B.R., Bittrich, V., Bove, C.P., Gustafsson, M.H.G., Philbrick, C.T., Rutishauser R., et al., 2011. Phylogeny of the clusioid clade (Malpighiales): evidence from the plastid and mitochondrial genomes. American Journal of Botany 98, 306325.

Sanderson, M.J., 1997. A nonparametric approach to estimating divergence times in the absence of rate constancy. Molecular Biology and Evolution 14, 1218-1231.

Sanmartin, I. 2003. Dispersal vs, vicariance in the Mediterranean: historica biogeography of the Palearctic Pachydeminae (Coleoptera, Scarabaeoidea) Journal of Biogeography 30, 1883-1897.

Sanmartin, I., Enghoff, H., Ronquist, F., 2001. Patterns of animal dispersal, vicariance and diversification in the Holarctic. Biological Journal of the Linnean Society 73 , 345-390.
Sanmartin, I., van der Mark, P., Ronquist, F., 2008. Inferring dispersal: a Bayesian approach to phylogeny-based island biogeography, with special reference to the Canary Islands. Journal of Biogeography 35, 428-449.

Sanmartín, I., Anderson, C.L., Alarcon, M., Ronquist, F., Aldasoro, J.J., 2010. Bayesian island biogeography in a continental setting: the Rand Flora case. Biology Letters 6, 703-707.

Sepulchre, P., Ramstein, G., Fluteau, F., Schuster, M., Tiercelin, J.J., Brunet, M., 2006. Tectonic uplift and Eastern Africa aridification. Science 313, 1419-1423.

Simmons, M.P., 2012. Misleading results of likelihood-based phylogenetic analyses in the presence of missing data. Cladistics 28, 208-222.

Simmons, M.P., Ochoterena, H., 2000. Gaps as characters in sequence-based phylogenetic analyses. Systematic Biology 49, 369-381.

Smith, S.A., Dunn, C.W., 2008. Phyutility: a phyloinformatics tool for trees, alignments and molecular data. Bioinformatics 24, 715-716.

Spach, E., 1836a. Conspectus monographiae Hypericacearum. Annales des Sciences Naturelles - Botanique et Biologie Vegetale 5, 349-369.

Spach, E., 1836b. Hypericacearum monographiae fragmenta. Annales des Sciences Naturelles - Botanique et Biologie Vegetale 5, 156-176.

Stamatakis, A., Hoover, P., Rougemont, J., 2008. A rapid bootstrap algorithm for the RAxML web servers. Systematic Biology 57, 758-771.

Stevens, P.F., 2007. Hypericaceae. In: Kubitzki, K. (Ed.), The Families and Genera of Vascular Plants. Springer, Berlin, Heidelberg, pp. 194-201.

Swofford, D.L., 2002. PAUP*: Phylogenetic Analysis Using Parsimony (* and Other Methods). Version.

Taberlet, P., Gielly, L., Pautou, G., Bouvet, J., 1991. Universal primers for amplification of three non-coding regions of chloroplast DNA. Plant Molecular Biology 17, 1105-1109.

Thiers, B., 2008. Index herbariorum: a global directory of public herbaria and associated staff. New York Botanical Garden. http://sweetgum.nybg.org/ih/.

Tiffney, B.H., 1985a. Perspectives on the origin of the floristic similarity between eastern Asia and eastern North America. Journal of the Arnold Arboretum 66, 73-94.

Tiffney, B.H., 1985b. The Eocene North Atlantic land bridge: its importance in Tertiary and modern phytogeography of the Northern Hemisphere. Journal of the Arnold Arboretum 66, 243-273.

Walker, J.D., Geissman, J.W., 2009. 2009 GSA geologic time scale. GSA Today 19, 60

Wang, Y.J., Susanna, A., Von Raab-Straube, E., Milne, R., Liu, J.Q., 2009. Island-like radiation of Saussurea (Asteraceae: Cardueae) triggered by uplifts of the Qinghai-Tibetan Plateau. Biological Journal of the Linnean Society 97, 893-903.

Wen, J., 1999. Evolution of eastern Asian and eastern North American disjunct distributions in flowering plants. Annual Review of Ecology and Systematics 30, 421-455.

Wen, J., Ickert-Bond, S.M., 2009. Evolution of the Madrean-Tethyan disjunctions and the North and South American amphitropical disjunctions in plants. Journal of Systematics and Evolution 47, 331-348.

White, T.J., Bruns, T., Lee, S., Taylor, J., 1990. Amplification and direct sequencing of fungal ribosomal RNA genes for phylogenetics. In: Innis, M.A., Gelfand, D.H. Sninsky, J.J., White, T.J. (Eds.), PCR protocols: a guide to methods and applications. Academic Press, San Diego, pp. 315-322.

Wiens, J.J., 2006. Missing data and the design of phylogenetic analyses. Journal of Biomedical Informatics 39, 34-42.

Wiens, J.J., Morrill, M.C., 2011. Missing data in phylogenetic analysis: reconciling results from simulations and empirical data. Systematic Biology $60,719-731$.

Wolfe, J.A., 1975. Some aspects of plant geography of the northern hemisphere during the Late cretaceous and Tertiary. Annals of the Missouri Botanical Garden 62, 264-279.

Wurdack, K.J., Davis, C.C., 2009. Malpighiales phylogenetics: gaining ground on one of the most recalcitrant clades in the angiosperm tree of life. American Journal of Botany 96, 1551-1570.

Xiang, Q.Y., Soltis, D.E., Soltis, P.S., 1998. The eastern Asian and eastern and western north American floristic disjunction: congruent phylogenetic patterns in seven diverse genera. Molecular Phylogenetics and Evolution 10, 178-190.

Zachos, J., Pagani, M., Sloan, L., Thomas, E., Billups, K., 2001. Trends, rhythms, and aberrations in global climate $65 \mathrm{Ma}$ to present. Science 292, 686-693.

Zhao, L.C., Wang, Y.F., Liu, C.J., Li, C.S., 2004. Climatic implications of fruit and seed assemblage from Miocene of Yunnan, southwestern China. Quaternary International 117, 81-89.

Zwickl, D.J., 2006. Genetic algorithm approaches for the phylogenetic analysis of large biological sequence datasets under the maximum likelihood criterion. Genetic algorithm approaches for the phylogenetic analysis of large biological sequence datasets under the maximum likelihood criterion. 